\title{
ARTÍCULOS
}

\section{EVOLUCIÓN DEL CÁLCULO DE LA LATITUD POR LA ALTURA MERIDIANA INCLUIDO EN LOS TEXTOS PARA LA FORMACIÓN DE LOS PILOTOS DE LA CARRERA DE INDIAS EN TIEMPO DE LOS AUSTRIAS.}

\author{
Gabriel Pintos Amengual \\ Universidad del País Vasco \\ mallorca1954@hotmail.com
}

Resumen: Durante los siglos XVI y XVII, los Regimientos de Navegación fueron los textos donde se formaron los pilotos de la Carrera de Indias. Por lo que su análisis constituye un instrumento eficaz, para conocer el grado de formación que recibieron y su evolución. Dentro de los conocimientos exigidos a los pilotos se incluía el cálculo de la latitud observada por altura meridiana del Sol, lo que conformó el primer método astronómico de posicionamiento, que se les enseñó a los pilotos de la Carrera de Indias. En este artículo nos adentramos en el análisis de ese método de posicionamiento astronómico y su evolución a través de los textos seleccionados. Finalmente presentamos las reglas empleadas por los diversos autores, en las que durante el periodo estudiado no varió el procedimiento utilizado.

Palabras clave: Pilotos de la Carrera de Indias, regimientos de navegación, reglas del sol, cálculo de la latitud por altura meridiana, Casa de la Contratación de Sevilla.

Tittle: EVOLUTION IN THE MERIDIAN HEIGHT CALCULATION DESCRIBED IN THE TEXTBOOKS USED IN THE EDUCATION OF PILOTOS DE LA CARRERA DE INDIAS IN HABSBURGS TIME.

Abstract: During the 16th and 17th centuries, the so-called "Regimientos de Navegación" were the textbooks used to educate the pilotos de la Carrera de Indias. Therefore, their analysis is an effective tool to know the degree of training they received and its evolution. Among the knowledge required of the pilots was the calculation of the observed latitude by the meridian height of the Sun, which was the first astronomical method of positioning taught to the pilots of the Carrera de Indias. In this article, we delve into the analysis of this method of astronomical positioning and its evolution through the selected texts. Finally, we present the rules used by the various authors in which the procedure used did not vary during the studied period.

Keywords: Pilotos de la Carrera de Indias, regimientos de navegación, rules of the sun, calculation of latitude by meridian height, Casa de la Contratación de Sevilla.

Cómo citar este artículo: PINTOS AMENGUAL, Gabriel. Evolución del cálculo de la latitud por la altura meridiana incluido en los textos para la formación de los pilotos de la Carrera de Indias en tiempo de los Austrias. Naveg@mérica. Revista electrónica editada por la Asociación Española de Americanistas [en línea]. 2020, n. 25. Disponible en: <http://revistas.um.es/navegamerica>. [Consulta: Fecha de consulta]. ISSN 1989-211X. 


\section{Introducción}

Después del descubrimiento de América, los viajes por mar trajeron significativos cambios, que repercutieron en todos los elementos que lo componían: pilotos, buques, instrumentos náuticos, etc.

Los conocimientos de la costa por donde se navegaba y la navegación de estima (rumbo y distancia), no eran suficientes para realizar la travesía, llegar al punto de destino y poder hacer el tornaviaje. La navegación alejada de la costa requirió que los pilotos adquirieran unos conocimientos científicos, para poder determinar la posición del buque y situarlo en la carta "echar el punto".

El descubrimiento de América planteaba el gran reto de la navegación oceánica. La navegación empírica, como se había hecho hasta entonces, de estima o a la vista de la costa, ya no eran suficientes. La regularidad de las rutas, la seguridad de las tripulaciones, de los medios y de las mercancías transportadas, requerían una navegación más precisa, basada en aplicaciones matemáticas para poder determinar la posición del buque, y la de las tierras descubiertas. Por lo que se recurrió a la observación del Sol (meridiana) y la Polar, para obtener por cualquiera de estos dos astros, su altura y poder calcular la latitud geográfica, mediante la utilización del astrolabio, el cuadrante y la ballestilla. Pasando de la navegación de fantasía (rumbo y distancia), al denominado punto de escuadría (latitud observada y rumbo).

Los españoles y los portugueses en sus viajes al Oeste y por la costa africana, fueron los primeros que utilizaron la Navegación astronómica, para lo cual se valieron de asgtrolabio y tablas de declinación del Sol. Así mismo, los portugueses, crearon las llamadas Guía de Munich (sobre el 1509) y la Guía de Évora (sobre 1516), que incluían los "Regimientos", conjunto de reglas que los pilotos tenían que utilizar, el "Regimiento del Sol" para calcular la latitud observada por altura meridiana, el "Regimiento de la Polar" para calcular la latitud por la altura de la Polar. También se incluía la traducción de la "Esfera de Sacrobosco", tablas de declinación del Sol y un derrotero de los lugares por donde habían navegado los portugueses con sus latitudes.

La mayor parte de los libros de navegación, se escribieron en relación inmediata o indirecta con la Casa de la Contratación de Sevilla, constituyendo una de las principales aportaciones españolas a la literatura científico-técnica de todos los tiempos. Estos textos fueron fundamentales para la formación de los pilotos de la Carrera de Indias y también en la de los pilotos europeos, como lo demuestran las ediciones que se hicieron del texto de Pedro Medina (1493 - 1567) en Francia, Italia, Inglaterra y Países Bajos, que sumaron un total de 20 ediciones entre los años 1554 y 1633, mientras que de la del texto de Martín Cortés (1510-1582) entre los años 1561 y 1630 se realizaron 9 ediciones en Inglaterra, lo que llevó a afirmar Guillen Tato "Europa aprendió a navegar en libros españoles", frase que dio título a su folleto sobre los Regimientos y Artes de Navegar de los siglos XVI y XVII.

${ }^{1}$ GUILLEN TATO, Julio Fernando. Europa aprendió a navegar en libros españoles. Barcelona: Contribución del Museo Naval de Madrid a la exposición del Libro del Mar, 1943, pp. 9-12. 
Mientras que el siglo XVI supuso una época de esplendor en la ciencia española, el siglo XVII, coincidiendo con el reinado de los Austrias Menores (15981700), fue de declive. Aunque en un contexto europeo, a esta etapa, se le reserva el calificativo de "revolución científica", marcado por la construcción de la física y la astronomía moderna, con astrónomos como Galileo, Kepler y Newton. Etapa en la que España quedó fuera del punto de partida de la "revolución científica" debido a los obstáculos que fueron creciendo a lo largo del siglo XVI, que la aislaron de las corrientes europeas imposibilitando su inserción en la sociedad ${ }^{2}$.

Por otra parte autores como Sánchez Martínez y Navarro Brotons consideran que el término de revolución científica va más allá de la construcción de la física y la astronomía, ampliándola a la geografía y la cartografía que experimentaron un gran desarrollo en los siglos XVI y XVII ${ }^{3}$. A lo que Navarro Brotons citando a la Dra. Ursula Lamb pone de manifiesto el desarrollo que tuvieron las ciencias de la naturaleza en la España de los Hamburgo, a lo que añade:

"A mí me gustaría concluir, de forma similar, diciendo que no se debería escribir la historia de la astronomía moderna, en particular, y de la ciencia, en general, ignorando la labor desarrollada por los pilotos y cosmógrafos portugueses y españoles." ${ }^{4}$

\subsection{El Piloto}

Desde tiempos pretéritos, el piloto ha sido el técnico náutico encargado de la derrota del buque. A estos profesionales encargados de dirigir la nave, se les ha denominado con diferentes nombres a través de la historia, como: naucher, marinero o piloto ${ }^{5}$. Atendiendo a las distintas denominaciones que ha recibido, nos aproximamos a la figura del piloto por medio de la siguiente definición:

"El que tiene a su cargo el govierno del navío, desde que se hace a la vela para algún viaje, hasta que surge ${ }^{6}$, y en eso le obedecen todos los marineros"7.

\footnotetext{
${ }^{2}$ LÓPEZ PIÑERO, José María. Ciencia y técnica en la sociedad española de los siglos XVI y XVII. Barcelona: Labor, 1979, pp. 371-372.

3 SÁNCHEZ MARTíNEZ, Antonio. La voz de los artesanos en el Renacimiento científico: Cosmógrafos y cartógrafos en el preludio de la nueva filosofía natural. Arbor Ciencia, Pensamiento y Cultura. May./jun., 2010, vol. CLXXXVI, p. 456. NAVARRO BROTONS, Víctor. Disciplina saberes y prácticas. Filosofía natural, matemáticas y astronomía en la sociedad española de la época moderna. Valencia: Universitat de Vàlencia, 2014, p. 239.

${ }^{4}$ NAVARRO BROTONS, Víctor. Disciplina, saberes y prácticas. Op. cit., p. 194.

${ }^{5}$ Véanse las diferentes denominaciones que recibe el piloto en: LÓPEZ, Gregorio. Las siete partidas del Rey Don Alfonso el Sabio. Cotejada por el Lic. Gregorio López. Vol. 2. Segunda y Tercera partida. París: Lecointe y Laserre, 1843, p. 285. LULIO, Raimundo. Arbol de la ciencia de el muy iluminado maestro Raymundo Lulio (Traducido por Alonso de Cepeda y Adrada). Bruselas: Francisco Foppens, Impresor y mercader de libros, 1664, p. 100. CAPMANY Y DE MONPALAU, Antonio. Código de las costumbres marítimas de Barcelona, hasta aquí vulgarmente llamado libro del consulado. Madrid: Imprenta de Don Antonio Sancha, 1791, pp. 32-33.

${ }^{6}$ GARCÍA DE PALACIO, Diego. Instrucción náutica, para el buen uso, y regimiento de las naos, su traza, y gobierno conforme a la altura de México. México: En casa de Pedro Ocharte, 1587, fol. 154. 'Surgir' es tomar puerto y lo mismo es dar fondo.

${ }^{7}$ GARCÍA DE PALACIO, Diego. Instrucción náutica... Op. cit., fol.151.
} 
En los inicios, los pilotos se clasificaron en función de las carreras para las que estaban examinados. A través de Veitia Linaje nos acercamos a las distintas carreras existentes y sus denominaciones y trayectos: Tierra Firme, que comprendía: el Cabo de la Vela, Santa Marta, Cartagena, Nombre de Dios y La Habana; Nueva España, que comprendía: la ruta de Santo Domingo y La Habana; y las Islas de Barlovento: constituidas por las islas septentrionales de las Pequeñas Antillas, entre las que están Granada, Martinica, Santa Lucía, Barbados, Guadalupe, Dominica, Trinidad y Tobago $^{8}$. Para cada una de las carreras el aspirante a piloto tenía que ser examinado. Pero aparte de estas derrotas había tantas como puertos de destino, "y así hay pilotos de Honduras, de Margarita, de Puerto Rico [...]", de los que ha inventariado 420 exámenes para pilotos, en los que se detalla para la carrera o carreras que se les habilitaba desde 1568, fecha de la que datan lo que califica de los primeros expedientes académicos de pilotos de la Carrera de Indias hasta $1600^{9}$.

Además de la clasificación a la que nos referimos en este apartado, existía la que se hizo en función de la habilitación que expedía la administración a los pilotos, conviene conocer los tres géneros de pilotos que distingue Escalante de Mendoza en función de los trayectos que realizaban: pilotos de río, son los que traen las naves desde el pasaje de Sevilla hasta aquí donde estamos; pilotos de barra son aquellos que nos llevan desde aquí hasta sacarnos de la barra de Sanlúcar y pilotos de mar, los que van navegando por esos golfos y mares largos en demanda de tierras muy lejanas y remotas ${ }^{10}$.

A las clases de pilotos descritas hay que añadir, asimismo, la que surgió debido a la escasez de pilotos examinados, que posibilitó a profesionales sin los requisitos exigidos para obtener la certificación correspondiente, poder pilotar las naves de la Carrera de Indias. Siguiendo a Pulido Rubio los distinguimos en: pilotos no examinados, aquellos que sin realizar ningún tipo de examen les fue suficiente demostrar que eran prácticos en la navegación; pilotos aprobados, los que sufrieron examen, pero sin seguir las Ordenanzas y pilotos acompañados, entre los que distingue dos tipos: los que estando examinados realizaban el viaje con otro más antiguo y los que sufrían un examen superficial para realizar un viaje determinado ${ }^{11}$.

\subsection{La Navegación}

La realización de los viajes oceánicos hizo imprescindible que los pilotos se familiarizasen con la utilización de los astros y los instrumentos de tomar alturas como medio para obtener las coordenadas geográficas en donde se encontraba el buque.

\footnotetext{
${ }^{8}$ VEITIA LINAJE, José. Norte de la Casa de Contratación de las Indias Occidentales. Sevilla: Juan Francisco de Blas, 1672, p. 154.

${ }^{9}$ NAVARRO GARCÍA, Luis. Pilotos, maestres y señores de naos en la carrera de las Indias. Revista histórica, literaria y artística. 1967, vol. 46, n. 141, pp. 258-275.

${ }^{10}$ ESCALANTE DE MENDOZA, Juan. Itinerario de navegación. Madrid: Museo Naval (1985), 1575, p. 56.

${ }_{11}$ PULIDO RUBIO, José. El Piloto Mayor de la casa de Contratación de Sevilla. Pilotos mayores, catedráticos de cosmografía y cosmógrafos. Sevilla: Escuela de Estudios Hispano Americanos, 1950, pp. 190-192.
} 
Para la determinación de la latitud por altura meridiana del Sol, era necesario tomar la altura de Sol sobre el horizonte, que normalmente se hacía con el astrolabio y el conocimiento de la declinación, que se obtenía de las tablas. En la esfera celeste de la Figura 1, se representa la posición del Sol a mediodía, es decir a su paso por el meridiano superior de lugar. La posición del observador en la superficie terrestre se corresponde en ésta con la de su zenit. Medida la altura del Sol con el astrolabio $\left(60^{\circ}\right)$ y tomada de una tabla su declinación $\left(10^{\circ}\right)$, las únicas operaciones requeridas eran: $90^{\circ}-60^{\circ}=30^{\circ}$ y $30^{\circ}+10^{\circ}=40^{\circ}$.

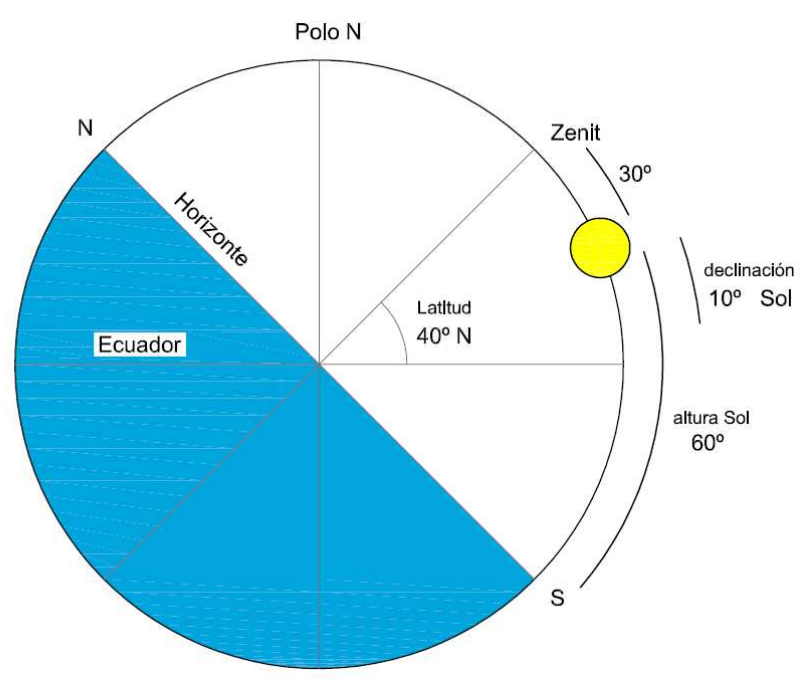

Fig. 1: Explicación gráfica del procedimiento para el cálculo de la latitud observada en el instante de la meridiana. Fuente: Elaboración propia.

En una primera fase de la navegación astronómica en el Atlántico, la utilización de la latitud observada y la carta náutica para situar el punto no fue simultánea, si no que según señala Taylor, lo que se utilizó fue la diferencia de altura de los astros para determinar el camino recorrido Norte - Sur, y las latitudes de puntos conocidos de la costa se utilizaron como referencias locales ${ }^{12}$. Se llegaron a construir tablas con la altura meridiana del Sol para determinados puntos, por ejemplo, Lisboa, de esta forma, al calcular la altura meridiana del Sol en la mar, por diferencia entre alturas, se podía calcular la distancia a la que se encontraban los puntos.

"Estos procedimientos permitían corregir en el sentido Norte - Sur la estima del camino recorrido y marcar sobre la carta portulana, sin necesidad de que ésta tuviera la graduación de latitudes, la posición correcta del barco."13

Para la realización de los viajes oceánicos, ese procedimiento para calcular la distancia, no fue suficiente, por lo que, los pilotos además de tomar alturas tuvieron que adquirir una serie de conocimientos que hasta la fecha, por el tipo de navegación que realizaban no eran necesarios. Conocimientos que recogieron los textos utilizados para la formación de los pilotos, como se ilustra en la Figura 2, para el caso de la latitud por altura meridiana del Sol, en donde se ve un observador

12 LAGUARDA TRIAS, Rolando Agustín. Comentarios sobre los orígenes de la navegación astronómica. Madrid: Consejo Superior de Investigaciones Científicas. Instituto Histórico de Marina, 1959 , p. 8.

${ }^{13}$ LAGUARDA TRIAS, Rolando Agustín. Comentarios... Op. cit., p. 9. 
tomando su altura y las tablas de declinación.

Para tratar de resolver los retos que planteaba la navegación de altura, la Corona española tomó medidas a través de la Casa de Contratación de Sevilla ${ }^{14}$, considerada por Lòpez Piñero uno de los centros europeos más importantes, en lo que se refiere a la ciencia aplicada del siglo XVI, junto con el Consejo de Indias y la Academia de matemáticas de Madrid ${ }^{15}$. En el seno de la Casa de Contratación se creó el cargo de piloto mayor en 1508, lo que significó un impulso importante para el desarrollo de la navegación, la enseñanza de los pilotos, la construcción de cartas marinas e instrumentos náuticos. Durante el siglo XVI, la Casa de Contratación se convirtió en un centro investigador y de enseñanza náutica, donde bajo la dirección del piloto mayor, colaboraron en las tareas técnicas el cosmógrafo mayor como responsable de la fabricación de los instrumentos náuticos y las cartas de marear, bajo la dirección del cual trabajaban los cosmógrafos y el catedrático de navegación y cosmografía para leer el arte de navegar.

"El siglo XVI es la edad de oro en el desarrollo de la historia del cargo de Piloto Mayor. Esto hemos afirmado más arriba y se comprueba con un estudio un poco razonado de la obra realizada por los hombres que por él desfilaron en el mencionado siglo. Tuvieron que luchar con todas las desventajas de los que principian, y poco a poco las fueron salvando; de su época y a los trabajos por ellos dirigidos o censurados, datan las primeras cartas de marear, los instrumentos para la navegación, la obra colosal del Padrón General, una de las glorias de la Casa de la Contratación, y los primeros derroteros para la navegación"16.

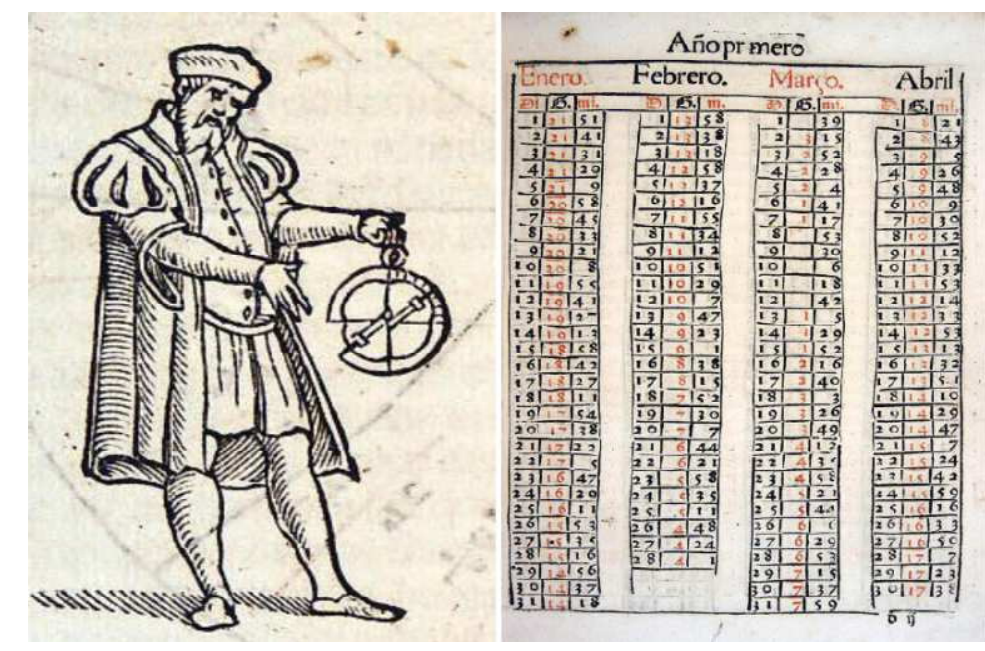

Fig. 2: Toma de altura del Sol y Tablas de declinación del Sol. Fuente: Regimiento de Navegación de Pedro Medina (1552) $)^{17}$.

\footnotetext{
${ }^{14}$ Para ver la importancia científica de esta institución consultar: PUENTE OLEA, Manuel. Los trabajos geográficos de la casa de la contratación. Sevilla: Escuela tipográfica y librería Salesianas, 1900.

${ }^{15}$ LÓPEZ PIÑERO, José María. Ciencia y técnica... Op. cit., p. 62.

${ }^{16}$ PULIDO RUBIO, José. El Piloto Mayor ... Op. cit., p. 15.

${ }^{17}$ MEDINA, Pedro. Regimiento de navegación. Contiene las cosas que los pilotos han de saber para bien navegar: y los remedios y avisos que han de tener para los peligros que navegando les pueden suceder. 1552, fols.s.n.
} 
Volviendo a la navegación oceánica, conocido el cálculo de la latitud, el de la longitud "altura lesteoeste" en la mar, tendría que esperar un par de siglos más, pero no surgió por generación espontánea, si no como un proceso investigador realizado en varios campos, fomentado a través del tiempo, desde países como España, Inglaterra, Portugal y Francia; llegándose a ofrecer importantes recompensas para quien resolviese el procedimiento por el cual se pudiese calcular la longitud geográfica, ya que se había convertido en un verdadero problema para cartógrafos, matemáticos y navegantes, afectando a la seguridad de la navegación, tanto es así, que con respecto al cálculo de la longitud muchos lo consideraron como límite puesto por Dios a la inteligencia humana"18 "Este es el punto celebre que Dios puso por termino del ingenio humano para su humillación, como las arenas del mar"19. Esta preocupación permaneció hasta la primera mitad del siglo XVIII, y los tratadistas así lo seguían reflejando.

Muchos años ha que se trabaja fin fruto en hallar la Longitud primariaen la Navegacion. El nudo Gordiano que no fe pudo disolver, lo pudo cortar la espada, y valor de Alexandro; pero efte problema defpues de tantos años permanece entero, de nadie resuelto ${ }^{20}$.

Los métodos de posicionamiento astronómico utilizados en la mar durante la época correspondiente a esta memoria, prácticamente permanecieron invariables, hasta la segunda mitad del siglo XVIII, que por el método de distancias Lunares y por cronómetros fue posible calcular la longitud en la mar, con lo que se deshizo la predicción de Zaragoza y los pilotos pudieron obtener las coordenadas geográficas que permitían situar la posición del buque.

\subsection{La formación de los Pilotos, siglos XVI-XVII}

Los nuevos requerimientos que conllevaba la navegación oceánica y la falta de preparación de los pilotos para realizarla con seguridad, motivó la promulgación de la Real Cédula de 6 de agosto de 1508 en la que se instituyó la figura del piloto mayor $^{21}$ dentro de la Casa de la Contratación de Sevilla ${ }^{22}$, este cargo ha sido

\footnotetext{
${ }^{18}$ Véanse: SALVÁ, M. y SAINZ DE BARANDA, Pedro. Colección de documentos inéditos para la historia de España. Vol. XXI. Madrid: Imprenta de la Viuda de Calero, 1852, pp. 221-222. REY PASTOR, Julio. La ciencia y técnica en el descubrimiento de América. Buenos Aires: Espasa Calpe, 1970, p.82.

${ }^{19}$ ZARAGOZA Y VILANOVA, José de. Esfera en común celeste y terráquea. Madrid: Juan Martín del Barrio, 1675, p. 249.

${ }^{20}$ CEDILLO Y RUJAQUE, Pedro Manuel. Tratado de cosmografía y nautica. Cádiz: En la imprenta Real de Marina y Casa de la Contratación de Don Miguel Gómez Guiraun, 1745, p. 102.

21 AGI, Indiferente, L.1, F.65V-67. AGI, Real Provisión a Américo Vespucio, piloto mayor, concediéndole facultad de examinar a los pilotos que hayan de ir a Indias, dándoles carta que los acredite como tales pilotos; y a los oficiales de la Casa de la Contratación para que hagan reunir a todos los pilotos más expertos y bajo la dirección de Américo Vespucio se reúnan los pilotos y rehagan el padrón general, dándole el nombre de padrón real. 1508-08-06, Valladolid.

${ }_{22}$ Real Provisión de los Reyes Católicos ordenando establecer en Sevilla una Casa de la Contratación y promulgando las primeras Ordenanzas para su gobierno. Alcalá de Henares, 20 de enero de 1503. AGI, Patronato, 251, R.1. La casa de Contratación de Sevilla creada para, entre otras funciones, estimular, encauzar y controlar el tráfico marítimo con el nuevo mundo, rasgos entre otros, que constituyeron los orígenes del mercantilismo castellano. Con respecto al mercantilismo: CORONA BARATECH, Carlos Eduardo Y ARMILLAS VICENTE, José Antonio. Historia General de
} 
considerado el primer puesto científico, al que se le asignaron las siguientes funciones: formar y examinar a los pilotos de la Carrera de Indias, dibujar y corregir las cartas náuticas y mejorar y perfeccionar los instrumentos de navegación. Al introducir la figura del piloto mayor, la Casa de Contratación de Sevilla se convirtió en un órgano centralizador de la actividad náutica. López Piñero califica este hecho como el inicio de la reglamentación del título de piloto como técnico en el arte de navegar $^{23}$. Fue a partir de ese momento, cuando de forma incipiente se estructuraron las enseñanzas náuticas, que en esta primera etapa conducía a la obtención de un título profesional, denominado Piloto de la Carrera de Indias. Hasta ese momento "la experiencia fue la única fuente de los conocimientos de un marino antes de la creación de la Casa de Contratación" ${ }^{\prime 2}$. La necesidad de tener a pilotos debidamente formados, para proteger las riquezas que venían del nuevo mundo, y la falta de centros de enseñanza náutica, donde formarlos, convirtió a la Casa de Contratación de Sevilla, en lo que posiblemente constituyó el primer centro de enseñanza a cargo del Estado, de la Historia Moderna ${ }^{25}$.

Para poder realizar trayectos oceánicos, desde ese momento, fue requisito indispensable obtener el título de Piloto de la Carrera de Indias. La mencionada Real Cédula de 1508, reflejaba en su parte inicial, como una verdadera exposición de motivos, las especificaciones sobre las materias que debían ser instruidos y la obligatoriedad de que se les expidiese carta de examen, sin la cual no podrían ser contratados para realizar dichos viajes ${ }^{26}$. De la misma forma establecía la posibilidad que el piloto mayor, en caso que faltasen pilotos examinados, pudiese habilitar por un tiempo determinado, a las personas que considerase más hábiles ${ }^{27}$. Quedaba así instituida la enseñanza que tenían que recibir los pilotos para poder navegar a Indias, en la que se dio una especificación muy genérica, de cómo tenía que ser esa formación "[...] sean instruidos y sepan lo que es necesario de saber en el cuadrante

España y América: La España de las Reformas Hasta el final del Reinado de Carlos IV. Vol. X-2. Madrid: Rialp, 1990, p. 20, señalan que hay dos manifestaciones de diferente signo: "Ramón Carande niega rotundamente que pueda atribuirse una política económica coherente a los gobernantes españoles del siglo XVI. En cambio, Earl J. Hamilton estima que antes de 1700 ya se habían adoptado en España todas las medidas de política económica mercantilista, salvo (y la excepción es importante) las reales fábricas y las compañías privilegiadas". Por otra parte VICENS VIVES, Jaime. Historia Económica de España. Barcelona: Vicens - Vives, 1977, pp. 282-283, para establecer los orígenes del mercantilismo castellano referencia a Hamilton, situando su origen en la época de los Reyes Católicos

${ }^{23}$ LÓPEZ PIÑERO, José. María. El Arte de Navegar en la España del Renacimiento. Barcelona: Labor, 1986, p.128.

${ }^{24}$ PÉREZ-MALLAínA, Pablo Emilio. Andalucía y el dominio de los espacios oceánicos. La organización de la Carrera de Indias en el siglo XVI. Fundación Corporación Tecnológica de Andalucía, 2010, p. 73.

${ }^{25}$ PÉREZ-MALLAínA, Pablo Emilio. Andalucía y el dominio de los espacios oceánicos. Op. cit., p.76.

${ }^{26}$ PULIDO RUBIO, José. EI Piloto Mayor ... Op. cit., p. 134.

${ }^{27}$ Véanse: FERNÁNDEZ DE NAVARRETE, Martín. Colección de los viages y descubrimientos que hicieron por mar los españoles desde fines del siglo XV. Vol. 3. Madrid: Imprenta Real, 1829, p. $302-$ 303. MENA GARCÍA, María del Carmen. Sevilla y las flotas de Indias: La Gran Armada de Castilla del Oro (1513-1514). Sevilla: Universidad de Sevilla; Fundación Cultural El Monte, 1998, p. 183, en donde el piloto mayor de la Casa de Contratación de Sevilla en 1512 presentó un informe "pidiendo para Juan Rodríguez Sardo, con experiencia en la navegación trasatlántica, un plazo de seis meses para que aprendiese a manejar el cuadrante o el astrolabio, quedando así acordado por los oficiales de la casa". De esta forma, quedaba garantizado el tráfico con las Indias, mientras los pilotos iban adquiriendo los conocimientos necesarios para conseguir la titulación exigida. 
e astrolabio, para que junta la platica con la teorica, $[\ldots]^{\prime 28}$. En la que no se olvidó de reseñar la importancia que tenía la práctica en la enseñanza de la profesión, ya que para acceder a los exámenes se estableció como requisito indispensable haber navegado como marinero una serie de viajes a Indias. Este requisito de realizar las prácticas de mar, para obtener la titulación profesional perdura en la actualidad.

Los contenidos teóricos que se debían superar para obtener el título de piloto, establecidos en la Real Cédula de 1508, estaban compuestos por: conocimiento y manejo de las tablas de declinación solar, reglas de la sombra producida por luz solar al tomar su altura y su desarrollo, normas para tomar la altura del Sol, determinación de la latitud por altura meridiana, normas para tomar la altura de la estrella Polar, determinación de la latitud por la estrella Polar, uso del astrolabio y cuadrante.

Mediante el conocimiento de estos contenidos teóricos, se adquirían las siguientes competencias: calcular la latitud por altura meridiana del Sol, calcular la latitud por la altura de la Polar, utilizar autónomamente el astrolabio y el cuadrante para calcular la altura del Sol y de la Polar. El resto de competencias necesarias para realizar una navegación segura, se presuponía se habían adquirido mediante la práctica, por los viajes realizados al Nuevo Mundo.

Los requisitos necesarios para conseguir el título de piloto se modificaron por Real Cédula de 2 de agosto de $1527^{29}$ estableciendo los siguientes: Ser natural de los reinos de Castilla; haber navegado seis años como mínimo a las Indias, que tenían que probar mediante testigos o escrituras y haber estado en la Isla Española, Cuba, Tierra Firme y Nueva España; tener carta de marear y saber echar el punto en ella, así como conocer los puntos de destinos y los rumbos; tener astrolabio y cuadrante; los conocimientos náuticos que debían conocer los pilotos y realizar examen, en el que tenían que presentar astrolabio, cuadrante, carta de marear y regimiento.

La Real Cédula de 1527 dirigida a Sebastián Caboto piloto mayor de la Casa de Contratación de Sevilla, está considerada como "un complemento necesario de lo que ya estaba legislado" ${ }^{30}$. A la vez que complementaba lo legislado, podríamos añadir que desarrolló el contenido de aquel genérico "sean instruidos y sepan lo que es necesario de saber en el cuadrante e astrolabio"31 especificando que los examinandos debían presentarse con sus instrumentos de observación, la adecuación de cada instrumento según el astro a observar, así como los conocimientos básicos para poder calcular la latitud por observación del Sol y de la Polar, saber situar la posición del buque en la carta y trazar el rumbo a puerto de destino. La parte práctica, además de venir determinada por el tiempo de navegación establecido para poderse examinar, había que demostrarlo mediante el conocimiento pormenorizado de las zonas por donde había navegado, llegando al detalle de un buen derrotero. De lo que

\footnotetext{
${ }^{28}$ PULIDO RUBIO, José. El Piloto Mayor ... Op. cit., p. 67.

${ }^{29}$ Real Cédula a Sebastián Caboto, piloto mayor, sobre las órdenes que ha de guardar en el examen de los pilotos de Indias (10 capítulos). 1527-8-2 Valladolid. AGI, Indiferente, 421, L.12, F.185V-187R.

${ }^{30}$ PULIDO RUBIO, José. El Piloto Mayor ... Op. cit., p. 143.

${ }^{31}$ PULIDO RUBIO, José. El Piloto Mayor ... Op. cit., p. 67.
} 
se infiere que los pilotos debían poseer los siguientes conocimientos teórico prácticos: reglas de la sombra producida por luz solar al tomar su altura y su desarrollo, normas para tomar la altura del Sol, determinación de la latitud por altura meridiana, normas para tomar la altura de la estrella Polar, Estrella del Norte y de las guardas y de su movimiento, determinación de la latitud por la estrella Polar, uso del astrolabio y cuadrante, determinar los rumbos por donde ha de navegar, determinar la posición del buque. La ampliación de los conocimientos exigidos añadió nuevas competencias como: determinar los rumbos para llegar de forma segura a los puertos, mediante la práctica por los viajes realizados, determinar las horas por "las guardas" y por el Sol y echar el punto en la carta. Este programa que puede parecer sencillo, en el que está ausente la utilización del aparato matemático, hay que circunscribirlo a la época en que se diseñó, los conocimientos del momento, y la escasa preparación previa de los aspirantes a pilotos.

Estos requisitos se extendieron a los maestres, quedando obligados a su cumplimiento por Real Cédula de 21 de mayo de 1534, siendo preceptivo para poder ejercer la profesión ${ }^{32}$. El requisito de nacionalidad para desempeñar los cargos de piloto y maestre estuvo vigente hasta la emisión de la Real Cédula de 2 de agosto de 1547, que permitía el ejercicio de la profesión a los extranjeros casados, con residencia familiar en España y en el caso de los solteros debían obtener carta de naturaleza antes de realizar el examen ${ }^{33}$.

Tras ser examinados por el piloto mayor de la Casa de Contratación, los aprobados, conseguían el permiso para hacer la Carrera de Indias, quedando ligados a ésta por contrato por el que se comprometían a la confidencialidad de rutas, cartografía y conocimientos de navegación, así como a la recopilación de datos náuticos en sus viajes. Antes de partir, estaban obligados a mostrar sus cartas, instrumentos (astrolabio y agujas) y regimientos de navegación para recibir el visto bueno del piloto mayor de la Casa de Contratación, lo que acabó dando lugar a un lucrativo negocio que ocasionó no pocas disputas, que han sido recogidas y analizadas por distintos autores ${ }^{34}$.

Transcurridos 44 años de la creación del cargo de piloto mayor, para formar y examinar a los pilotos de la Carrera de Indias, se creó el cargo de catedrático de cosmografía para el que se nombró al bachiller Jerónimo de Chaves, por medio de la Real cédula de 4 de diciembre de $1552^{35}$.

Los requisitos necesarios para conseguir el título de piloto cada vez fueron más exigentes, por la pérdida de buques y vidas humanas en la mar, lo que constituía un elevado coste material y humano, inconvenientes atribuidos a la deficiente formación

\footnotetext{
${ }^{32}$ PULIDO RUBIO, José. El Piloto Mayor ... Op. cit., p. 159.

${ }^{33}$ PULIDO RUBIO, José. El Piloto Mayor ... Op. cit., pp. 57-58.

34 Véanse: FERNÁNDEZ DURO, Cesáreo. Disquisiciones Náuticas. Arca de Noé. Vol. 6. Madrid: Imprenta, Estereotipia y Galvanoplastia de Aribau y C. Sucesores de Rivadeneyra, 1881. MARTíNMERÁS, Luisa. Las enseñanzas náuticas en la Casa de la Contratación de Sevilla. En: ACOSTA, A.; GONZÁLEZ, A. y VILA, E. (coord.) La Casa de la Contratación y la navegación entre España y las Indias. Sevilla: Universidad de Sevilla; CSIC; Fundación El Monte, 2004, pp. 667-693.

${ }^{35}$ Nombramiento de Jerónimo de Chaves como cosmógrafo y catedrático de Cosmografía de la Casa de la Contratación. 1552-12-4 Monzón. AGI. Contratación, 5784, L.1, F.95-95V.
} 
de los pilotos de la Carrera de Indias ${ }^{36}$. Persistía así el problema que, en 1508, había motivado que se facultara al piloto mayor para formar y examinar a los pilotos. Las investigaciones realizadas tras los naufragios de los navíos de la Carrera de Indias mostraron que los motivos que con mayor frecuencia causaron estos 'inconvenientes' fueron: la sobrecarga de los buques, deficiencias en las carenas, falta de tripulantes expertos, errores de los pilotos y el estado de la mar ${ }^{37}$. Céspedes del Castillo por su parte, asegura que la Carrera de Indias destacó por su seguridad, soportado por la estimación realizada por García Baquero sobre datos de Chaunu, en la que la pérdida de buques que efectuaban la Carrera de Indias se situó en torno al $3 \%$ entre 1546 y 1650 . Señala este autor que un $80 \%$ de los naufragios se debieron al estado de la mar y errores de navegación y un $20 \%$ tuvieron lugar como resultado de ataques enemigos (piratas, corsarios y acciones de guerra) ${ }^{38}$. Para paliar la situación motivada por los errores de los pilotos se instituyeron en 1552 una serie de medidas, entre las que destacaron: separación del piloto mayor de la formación de los pilotos; creación del cargo de catedrático de cosmografía, impartición de la lectura de la cátedra en el seno de la Casa de Contratación; fijación de la duración de la formación de los pilotos, en un año, con establecimiento de un calendario escolar y ampliación del programa formativo.

Con la creación de la cátedra de cosmografía y la elección para el cargo del bachiller Jerónimo de Chaves, se optó por un perfil científico-técnico, frente al perfil práctico de los pilotos mayores, que hasta ese instante se habían encargado de la formación de los pilotos "En adelante, la cosmografía, custodiada por individuos formados en universidades castellanas y no en el mar [...]"39 y así se continuó en los sucesivos nombramientos ${ }^{40}$.

La citada Real Cédula de 1552, institucionalizó la obligación de asistir a la lectura de cosmografía y arte de navegar en la Casa de la Contratación de Sevilla durante un año. Este año de formación, se redujo a tres meses, a instancias de Jerónimo de Chaves. En solicitud dirigida al Rey, Chaves argumentaba que los conocimientos que él enseña pueden ser aprendidos en tres meses y que los que tenían que asistir a la lectura eran gentes pobres, que no tenían medios suficientes

36 SÁNCHEZ MARTÍNEZ, Antonio. Los métodos pedagógicos de la Corona para disciplinar la experiencia de los navegantes en el siglo XVI. Anuario de estudios americanos. 2010, vol. 67, n. 1, p. 136.

${ }^{37}$ PÉREZ-MALLAÍNA BUENO, Pablo Emilio. Naufragios en la Carrera de Indias durante los siglos XVI y XVII: El hombre frente al mar. Sevilla: Universidad de Sevilla, 2015, p. 67.

38 CÉSPEDES DEL CASTILLO, Guillermo. La defensa de América. En: RUIZ MARTíN, F. La monarquía de Felipe II. Madrid: Real Academia de la Historia, 2003, pp. 381-412.

${ }^{39}$ SÁNCHEZ MARTÍNEZ, Antonio. Los artífices del Plus Ultra: Pilotos, cartógrafos y cosmógrafos en la Casa de la Contratación de Sevilla durante el siglo XVI. Hispania. Revista Española de Historia. 2010, vol. LXX, p. 617.

${ }^{40}$ El primero que fue designado para desempeñar el puesto fue Américo Vespucio (1454-1512), al que le siguieron Juan Díaz de Solís (1470-1516) y Sebastián Caboto (1477-1577) cerrando el círculo de pilotos mayores exploradores, como les denominó Pulido Rubio (1950), para dar paso a un perfil más científico como los de Alonso de Chaves (ca. 1493-1587), Rodrigo Zamorano (1542-1620), Andrés García de Céspedes (ca.1545-1611), Diego Ramírez de Arellano (1580-1624), Antonio Moreno ( $¿$ ?- 1624), Francisco de Ruesta ( $¿$ ?-1673), Juan Cruzado de la Cruz y Mesa ( $i ?-1692)$, Juan de Saavedra ( $i$ ?-1666), Alonso de Bacas Montoya ( $i ?-1707)$. 
para poder subsistir este tiempo ${ }^{41}$. Esta petición fue concedida por Real cédula de 3 de junio de 1555. La obligación de asistir un año a la lectura de la cátedra fue una acción ineficaz al tratarse de gente pobre que por sus escasos medios económicos no podían permitirse el permanecer un año estudiando sin recibir ningún tipo de ingreso para su sustento ${ }^{42}$.

No siendo suficiente la reducción realizada se volvió a modificar de nuevo por Reales Cédulas de 6 de octubre de 1567 estableciendo el periodo de formación en 2 meses y por la de 25 de febrero de 1568 se mantuvo el periodo de 2 meses para oír la lectura de la cátedra, pero en el cómputo se incluyeron los festivos ${ }^{43}$. A pesar de la obligatoriedad de asistir a la lectura de la cátedra de cosmografía, para poder examinarse de piloto, no siempre se cumplió y durante todo el periodo que estuvo vigente, se autorizaron dispensas, eximiendo de la asistencia a clase, permitiendo el examen a aquellos que demostraban experiencia en la navegación ${ }^{44}$.

La Real Cédula de 4 de diciembre de 1552, desarrollaba la enseñanza que debían recibir los pilotos, con una estructura de plan estudios, en la que se distinguen tres bloques de contenidos: Astronomía y Geografía; Navegación Astronómica y Navegación de Estima y Costera. Empleando la terminología actual, finalizado el curso con éxito, los pilotos habían adquirido las siguientes competencias: calcular la latitud por altura meridiana del Sol; calcular la latitud por la altura de la Polar; determinar los rumbos para llegar de forma segura a los puertos; determinar las horas por "las guardas" y por el Sol; utilizar autónomamente el astrolabio, el cuadrante y la ballestilla para poder calcular la altura del Sol y de la Polar; conocer de forma pormenorizada la ruta marítima a realizar; echar el punto en la carta, determinar la situación del buque utilizando las técnicas de la navegación de estima; planificar las entradas y salidas de puerto, teniendo en cuenta las mareas (Tabla Lunar de Mareas) y utilizar autónomamente y construir los instrumentos, las cartas náuticas planas, otros sistemas de información y datos necesarios para la planificación y control de la derrota.

En esta Real Cédula además de establecer los conocimientos necesarios para que los pilotos supiesen "echar el punto", procuraba que recibiesen nociones elementales de Geografía y Astronomía, contenidas en el Tractatus Sphaerae (1250) de Juan de Sacrobosco (ca. 1195 - 1256).

El plan de estudios de 1552 se trata de un programa muy amplio para ser cursado en un año, su condensación en dos meses produjo que muchos de los pilotos no tuviesen la formación necesaria para ejercer la carrera, lo que implicó que:

\footnotetext{
${ }^{41}$ Véanse: PULIDO RUBIO, José. El Piloto Mayor... Op. cit., pp. 80-82 y MEDINA, José Toribio. El Veneciano Sebastián Caboto al servicio de España. Vol. 1: Texto. Santiago de Chile: Imprenta y Encuadernación Universitaria, 1908, pp. 305-306.

${ }^{42}$ SALAVERT FABIANI, Vicent Lluis. La cultura científico técnica en la España de los siglos XVI y XVII. Bulletin Hispanique. 1995, vol. 97, n. 1, p. 239.

${ }^{43}$ Véanse: VEITIA LINAJE, José. Norte de la Casa... Op. cit., p. 145 y ANÓNIMO. Recopilación de las leyes de los Reinos de las Indias, mandada imprimir y publicar por la Magestad Católica del Rey Don Carlos II, Nuestro Señor. Vol. III. Madrid: Boix, 1841, p. 305.

${ }^{44}$ PULIDO RUBIO, José. El Piloto Mayor ... Op. cit., pp. 153-154.
} 
"En 1603, tras un informe del Cosmógrafo Mayor del Consejo de Indias y del Catedrático de la Academia de Madrid, se volvió a exigir que los aspirantes a pilotos acudiesen a las lecturas del Catedrático un año completo, tal y como había establecido la Real Cédula de Felipe II de 1552" ${ }^{45}$.

No obstante, no hemos encontrado en el Archivo de Indias documentación que soporte que, a partir de 1603, se siguiese el requisito de oír la cátedra durante un año, al menos no en todas las ocasiones. De acuerdo con Pintos e lbáñez el requisito de oír dos meses la lectura de la cátedra de cosmografía perduró mientras el piloto mayor de la Casa de Contratación efectuaba los exámenes de Piloto de la Carrera de Indias ${ }^{46}$.

Parece incomprensible, que pese a lo amplio del programa diseñado y el fin para el que se ideó, el propio Jerónimo de Chaves recomendara la reducción del tiempo de lectura. Tampoco se comprende que, además, se estableciese que a los que tenían que examinarse de pilotos les bastaba saber leer el regimiento y firmar sus nombres.

"Los que han de ser examinados para pilotos de la carrera hayan oido la cátedra de cosmografía de la casa de Sevilla dos meses, contando las fiestas y cursando en ella, y en el arte de marear, con la fábrica y uso de instrumentos de navegación de aquellos viajes, como ahora se practica: y baste que sepan leer el regimiento de la navegación, y firmar sus nombres, con que en lo demás tengan la habilidad y suficiencia que se requiere $[\ldots]^{\prime \prime 4}$.

El Real Consejo de Indias $^{48}$ en el ejercicio de sus funciones gubernativas, en 1636 estableció un plan de estudios de una duración de tres años, para la enseñanza de Cosmografía ${ }^{49}$. Un plan de estudios importante que intentaba dar al piloto una formación completa, de carácter científico técnico, en el que se incluían los conocimientos que según Esteban Piñero ya señalaba Juan Herrera (1530 1597) en 1588 sobre lo que debían conocer los pilotos, consistentes en: el estudio de la Esfera, las teóricas de los planetas, la geografía de Ptolomeo, uso y fundamento del astrolabio, cuadrante, ballestilla y la aguja, además de la Geometría de Euclides ${ }^{50}$. En la Tabla 1, se detallan las materias contenidas en el plan y su

${ }^{45}$ ESTEBAN PIÑEIRO, Mariano. Ciencia Imperial: Casa de Contratación. El Escorial. El Alcázar. En: SARAIVA, T. y VALVERDE, N. Momentos y lugares de la ciencia Española siglos XVI-XX. Madrid: Antonio Lafuente y Juan Pimentel, 2012, p. 24.

${ }^{46}$ PINTOS, Gabriel y IBÁÑEZ, Itsaso. Antonio de Gaztañeta e Iturribalzaga (1656-1728): Notas biográficas inéditas. Llull, Revista de la Sociedad Española de Historia de las Ciencias y de las Técnicas. 2019, vol. 42, n. 86, pp. 99-119.

${ }^{47}$ ANÓNIMO. Recopilación de Leyes de los Reynos de las Indias mandadas imprimir, y publicar por la Magestad Católica del Rey Don Carlos II Nuestro Señor. Vol. I. Madrid: Julián de Paredes, 1841, p. 305.

${ }^{48}$ El Real Consejo de Indias se creó dentro del Consejo de Castilla por Real cédula de 14 de septiembre de 1519. En 1524, bajo la presidencia del cardenal Juan García Loaysa y Mendoza (14781546), se organizó de forma independiente. Desde su creación, entre sus funciones se encontraban la ejecutiva, la legislativa, la judicial y la de asesoramiento al Rey en las cuestiones que afectaban a las Indias. Sobre el Real Consejo de Indias destacamos la obra de: SCHAFER, Ernesto. El Consejo Real y Supremo de la Indias: Historia y organización del Consejo y de la Casa de la Contratación de las Indias. Madrid: Marcial Pons, Ediciones de Historia, 2003. 2 Volúmenes.

${ }^{49}$ ANÓNIMO. Recopilación de Leyes de los Reynos de las Indias mandadas imprimir, y publicar por la Magestad Católica del Rey Don Carlos II Nuestro Señor. Vol. I. Op. cit.

50 ESTEBAN PIÑEIRO, Mariano. Las academias técnicas en la España del siglo XVI. Quaderns 
duración. Se puede observar que la enseñanza se estructura de forma adecuada conteniendo los conocimientos necesarios para formar pilotos. Muy alejado en su estructura y contenido del plan vigente en la época ideado por la Casa de Contratación de Sevilla. El programa de estudios diseñado por el Real Consejo de Indias en 1636 ha sido considerado muy completo: "hay que esperar a las enseñanzas impartidas en el Colegio de San Telmo, ya iniciado el siglo XVIII, para encontrar una estructura semejante" ${ }^{\prime 51}$. Más absoluto es Guillén Tato al considerar que es el mejor plan de estudios de náutica, cuando expresa:

"Yo vuelvo a maravillarme de toda la seriedad de esta plan, quizá no superado relativamente en las actuales Escuelas de náutica; pero más bien para dolerme, acto seguido, al comunicaros que, mediado el siglo XVII, los tres años se convirtieron en tres meses, y hasta éstos se consideraron excesivos y quedaron reducidos tan sólo a uno $[\ldots]^{5,52}$.

\begin{tabular}{|c|c|c|}
\hline \multicolumn{3}{|c|}{ Cuadro asignaturas del plan del Real Consejo de Indias de 1636} \\
\hline Curso & Periodo & Contenidos \\
\hline \multirow{3}{*}{ 1er año } & Septiembre/Navidad & $\begin{array}{l}\text { La Esfera y las } 4 \text { reglas de aritmética, regla de tres y } \\
\text { raíz cúbica }\end{array}$ \\
\hline & Navidad/ Fin de Abril & Teórica del Sol y de la Luna de Jorge Purbaquio \\
\hline & Mayo/Fin de Junio & Tablas del Rey Alfonso \\
\hline \multirow{4}{*}{$2^{\circ}$ año } & $\begin{array}{l}\text { Septiembre/Fin de } \\
\text { Febrero }\end{array}$ & Seis primeros libros de Euclides \\
\hline & Marzo/Marzo & Arcos y cuerdas, senos rectos, tangentes y secantes \\
\hline & Abril/Abril & $\begin{array}{l}\text { El libro cuarto de los triángulos esferales de Juan de } \\
\text { Monte-Regio }\end{array}$ \\
\hline & Mayo/Fin de Junio & Lo que alcance del Almagesto de Ptolomeo \\
\hline \multirow{3}{*}{ 3er año } & Septiembre/Navidad & Cosmografía y Navegación \\
\hline & $\begin{array}{l}\text { Navidad/Pascua de } \\
\text { Resurrección }\end{array}$ & Uso y fabricación del Astrolabio \\
\hline & $\begin{array}{l}\text { Pascua de } \\
\text { Resurrección }\end{array}$ & $\begin{array}{l}\text { Modo de hacer observaciones de Sol, Luna y demás } \\
\text { planetas. Uso del Radio Globo y demás instrumentos } \\
\text { matemáticos }\end{array}$ \\
\hline
\end{tabular}

Tabla 1: Cuadro asignaturas del plan del Real Consejo de Indias de 1636. Fuente: Elaboración propia a partir de información tomada de Anónimo. Vol. I. ${ }^{53}$.

dl'historia de lénginyeria. 2002, n. 5, p. 11. Los elementos de Euclides es una obra compuesta por 13 capítulos con los siguientes contenidos: los libros del I al IV con 467 teoremas sobre geometría plana; del V al VI teoría de la proporción; del VII al X teoría de los números y del XI al XIII geometría del espacio.

51 ARROYO RUIZ-ZORRILLA, Ricardo. Apunte para una historia de la enseñanza de la náutica en España. Madrid: Centro de Publicaciones del Ministerio de Transportes Turismo y Comunicaciones, 1989 , p. 53.

${ }^{52}$ GUILLÉN TATO, J. F. La Náutica española en el siglo XVII. Madrid: Gráfica Universal, 1935, p.37.

${ }^{53}$ ANÓNIMO. Recopilación de Leyes de los Reynos de las Indias. Vol. I, Op. cit., p. 207. Los criterios que se han seguido para la elaboración del cuadro horario han sido: 1 . A efectos de calcular la fecha de Pascua de resurrección, consideramos el inicio del 1er año de docencia en 1637; 2.Pascua de Resurrección 1639 el 24 de abril; 3. Clases de una hora diaria de lunes a viernes; 4.Vacaciones los meses de julio y agosto; 5. Materias y horarios que señala la Ordenanza 242 de 1636. 
También Sánchez Martínez describe que el plan de estudios para alcanzar el grado de piloto eran de tres años y detalla los periodos lectivos por anualidad ${ }^{54}$, a pesar que este plan, nunca se puso en marcha. Desconocemos los motivos por los que no entró en vigor, pero sin duda su alto nivel de exigencia, su duración, y el estamento al que pertenecían los que se dedicaban a la mar, que no les permitía estar largos periodos inactivos, debieron ser factores determinantes para que ni siquiera se pusiese en marcha.

\title{
1.4. Exámenes
}

En la Cédula fundacional del cargo de piloto mayor de la Carrera de Indias, expresaba que se instituía esta figura para enseñar y examinar a los pilotos, fijaba el lugar en donde debía enseñarlos, y establecía que tenía que cobrar por impartir las lecciones "mandamos que les enseñéis en vuestra casa, en Sevilla, a todos los que quisieran saber, pagandovos vuestro trabajo",55. Quedaba constituido el cargo: piloto mayor de la Carrera de Indias, pero no establecía cómo debían ser los exámenes ni donde se debían realizar. Consultados autores como: Medina, Pulido Rubio, Navarro García, López Piñero o Arroyo, no hemos encontrado información que detalle el lugar donde se debía realizar, ni el procedimiento a seguir. La emisión de la Real Cédula de 2 de agosto de 1527, constituye la institucionaliza del lugar donde se debían celebrar los exámenes, la composición del tribunal, y los procedimientos:

\begin{abstract}
"Que al tiempo del examen de cada cual piloto, se ayuntarán en casa de vos, el dicho piloto mayor, todos los pilotos que hobiere á la sazón en la dicha ciudad de Sevilla, para el día é hora que el dicho piloto mayor les señalare, é ansí ayuntados, cada cual por su ciencia harán al que se quisiere examinar dos preguntas de lo tocante á la dicha arte de pilotaje, é será obligado á responder é absolvellas" $" 56$.
\end{abstract}

Constituido el tribunal, se realizaban las preguntas, una vez terminada la ronda de preguntas se pasaba a votar, en función de la mayoría de los votos se daba o no el grado de piloto y se le expedía la carta de examen. Siguiendo a Medina y a Pulido Rubio no cabe ninguna duda que el centro de enseñanza y examen en esta etapa continuaba siendo la casa del piloto mayor, como así lo determinaba la Real Cédula de 6 de agosto de 1508 "[...] mandamos que les enseñéis en vuestra casa, en Sevilla, a todos los que lo quisieren saber, pagandovos vuestro trabajo; $[\ldots]^{37}$ y lo confirmaba la Real Cédula de 2 de agosto de 1527, al referirse al lugar donde se celebraron los exámenes, quien debe asistir y del número de cuestiones a preguntar. Al realizarse los exámenes en la casa del piloto mayor considera Navarro García que estaban desprovistos de carácter oficial, las clases se estipulaban por contrato verbal entre las partes y cuando se consideraba que los aspirantes a pilotos estaban preparados, se les expedía el título de piloto de la Carrera de Indias, "mediando o sin mediar examen" ${ }^{\prime \prime}$. El título de piloto adquiere adquiere carácter oficial cuando se ordena que se realicen en la Casa de Contratación. Lo que no parece probable es

\footnotetext{
${ }^{54}$ SÁNCHEZ MARTíNEZ, Antonio. Los métodos pedagógicos de la Corona. Op. cit., pp. 138-139.

${ }^{55}$ PULIDO RUBIO, José. El Piloto Mayor ... Op. cit., p. 67.

${ }^{56}$ MEDINA, José Toribio. El Veneciano ... Op. cit., p. 505.

${ }^{57}$ PULIDO RUBIO, José. El Piloto Mayor ... Op. cit., p. 462.

${ }^{58}$ NAVARRO GARCÍA, Luis. Pilotos ... Op. cit., p. 252-253.
} 
que se expidiesen títulos de piloto de la Carrera de Indias, sin el preceptivo examen, ya que la referida Real Cédula de 2 de agosto de 1527, establecía entre otras condiciones, además del piloto mayor, la presencia de todos los pilotos que hubiese en la ciudad de Sevilla, así como la de escribano público para recoger los votos secretos y extender la carta de examen teniendo que firmarla junto con el piloto mayor, expresando el detalle de todas las particularidades ocurridas ${ }^{59}$.

Volviendo al lugar de examen, a Alonso de Chaves se le concedió por Real cédula de 21 de agosto de 1528, dar clases en su posada, como ya lo venía haciendo, las enseñanzas que impartía eran sobre el astrolabio, el cuadrante y la carta de marear, el tratado de la esfera, que preparaban al aspirante a piloto de la carrera de Indias para superar el examen. La Ordenanza 128 de la Casa de Contratación de Sevilla de 1553 ordenaba que el examen se realizase en la casa de la Contratación, al no cumplirse el mencionado precepto llevó al comendador Diego de Zárate a petición del cosmógrafo Sancho Gutiérrez a recodar que ciertos capítulos de las ordenanzas de 1543, que había hecho el licenciado Gregorio López y en concreto el referente al de la realización de los exámenes en la Casa de Contratación no se cumplían. Las clases se siguieron realizando en la casa del piloto mayor hasta el 21 de enero de 1553 en que quedo habilitada la capilla de la Casa de Contratación, lugar designado para la impartición de las clases ${ }^{60}$.

De acuerdo con las Ordenanzas de la Casa de Contratación de Sevilla de 1553, las instrucciones que tenían que observarse en los exámenes de pilotos eran las siguientes:

- Lugar de examen: La Casa de la Contratación de Sevilla ${ }^{61}$.

- Requisitos: Oír dos meses la Cátedra de Navegación ${ }^{62}$; natural de estos Reinos ${ }^{63}$, mayor de 24 años de edad, de buenas costumbres, haber navegado a las Indias como mínimo durante seis años, presentación de cuatro testigos de los cuales como mínimo dos debían ser pilotos con los que debía haber navegado y con disposición de encomendarle su barco en caso de necesidad ${ }^{64}$.

- Tribunal de examen: El piloto mayor, dos cosmógrafos y los pilotos presentes en la ciudad (no inferior a seis) ${ }^{65}$. El piloto mayor se dispondrá en el centro, el cosmógrafo más antiguo a su derecha, el más moderno a su izquierda y los demás pilotos por orden de antigüedad ${ }^{66}$.

- Procedimiento: El piloto mayor y los cosmógrafos podían hacer el número de preguntan que considerasen oportuno, mientras que los pilotos sólo podrían realizar tres preguntas ${ }^{67}$. En el examen de pilotos el piloto mayor y cosmógrafos votaban por haba y altramuz, si salían más habas que altramuces el piloto resultaba aprobado y reprobado en caso contrario y de empate, el reprobado no

\footnotetext{
${ }^{59} \mathrm{AGI}$, Indiferente, 421, L.12, F.185V-187R.

${ }^{60}$ PULIDO RUBIO, José. El Piloto Mayor ... Op. cit., pp. 83-84, 132-133.

${ }^{61}$ Artículos 128 y 143 de las Ordenanzas reales para la Casa de la Contratación de Sevilla de 1553.

${ }^{62}$ Real Cédula de 25 de febrero de 1568.

${ }^{63}$ AGI. Indiferente, 1961, L.3, F.183R-183V.

${ }^{64}$ Artículo 135 de las Ordenanzas reales para la Casa de la Contratación de Sevilla de 1553.

${ }^{65}$ Artículo 128 de las Ordenanzas reales para la Casa de la Contratación de Sevilla de 1553.

${ }^{66}$ Artículo 134 de las Ordenanzas reales para la Casa de la Contratación de Sevilla de 1553.

${ }^{67}$ Artículo 137 de las Ordenanzas reales para la Casa de la Contratación de Sevilla de 1553.
} 
podía volver a examinarse hasta cumplimentar dos viajes a la Indias y los aprobados no podían ser examinadores ni votar en el examen de piloto hasta realizar un viaje a las indias ${ }^{68}$.

- Expedición del título: Al aprobado se le expedía título con especificación de cómo fue examinado ${ }^{69}$.

Conocemos cómo se realizaban los exámenes para pilotos en la Casa de la Contratación por el manuscrito que realizó Alonso de Chaves de 1560 a 1561 sobre Relación de la orden que observaba en el examen y admisión de los pilotos y maestres de Indias en Sevilla, documento que resulta esclarecedor para poder determinar el grado de aplicación del plan de estudios de 1552, cuando se refiere a las preguntas que les hacía a los aspirantes a pilotos, dice: "[...] yo les hago todas las preguntas que me parecen ser necesarias en las reglas del sol y el norte, lunas y mareas, instrumentos, sondas y derrotes, y echar punto de la carta y uso de ellos [...]"70. Por lo que, se deduce, que el nivel de exigencia en los exámenes de los pilotos, poco había variado con respecto al de 1527, a pesar de haber confeccionado un plan de estudios, que podía considerarse adecuado para su tiempo, pero por las razones expuestas, se acortó de forma drástica el periodo de oír la cátedra, lo que debió implicar acortar en la misma medida los contenidos. Con lo cual la reorganización de los estudios queda cuestionada, al quedar prácticamente los mismos contenidos que en la Cédula de 1527.

\subsection{Objetivos}

El propósito de este trabajo es realizar un estudio histórico, delimitado cronológicamente entre el 1508 y 1700, sobre el cálculo de la latitud observada por altura meridiana en los textos que se utilizaron en la formación de los pilotos en el tiempo de los Austrias. En donde se pretende conseguir los siguientes objetivos:

- Describir los métodos utilizados.

- Conocer su evolución.

- Verificar el grado de conocimientos sobre astronomía de posición utilizados en la formación de los pilotos.

Para conseguir los objetivos propuestos, realizamos una recopilación de los textos que se utilizaron en la formación de los pilotos de acuerdo con unos determinados criterios establecidos, para poder analizarlos, compararlos y finalmente presentar los resultados y conclusiones.

\section{Metodología}

Este artículo se enmarca en la línea de investigación que estamos realizando sobre los textos editados para la formación de los pilotos de la Carrera de Indias en tiempo de los Austrias. Para llevar a cabo esta investigación hemos seguido el método histórico, en cada una de sus fases: la heurística, la crítica, la hermenéutica

\footnotetext{
${ }^{68}$ Artículos 139 y 140 de las Ordenanzas reales para la Casa de la Contratación de Sevilla de 1553.

${ }^{69}$ Artículo 128 de las Ordenanzas reales para la Casa de la Contratación de Sevilla de 1553.

${ }^{70}$ NAVARRO GARCÍA, Luis. Pilotos ... Op. cit., p. 247.
} 
y la exposición.

En la fase heurística hemos realizado una búsqueda de la bibliografía relacionada con el tema acudiendo a bases de datos, bibliotecas físicas y virtuales, así como a diversos buscadores y repositorios virtuales. Realizada la localización de la bibliografía, procedemos a constituir la documentación básica contenida en las obras de: Fernández de Navarrete, Picatoste, Gelcich, Guillen Tato, Palau Claveras, García Franco, López Piñero, Capel, Arroyo, Gonález, Cerezo Martínez, Ibáñez, Iglesias, Martín Merás y Manterola. La información obtenida en la bibliografía seleccionada nos ha permitido tener un rol de obras catalogadas, con el que se ha constituido un catálogo de textos de Náutica de acuerdo con los siguientes criterios:

- Trabajos impresos editados en España.

- Editados entre el siglo XVI y XVII, primera edición.

- Dedicados al Arte de Navegar, "Pilotage", en el que se incluyen las obras de traça de naos y Arquitectura Naval, así como las obras de matemáticas editadas para el estudio del "Pilotage" (Aritmética, Geometría y Trigonometría).

A partir de la información obtenida se ha confeccionado un primer catálogo de textos náuticos, entre los cuales hemos seleccionado aquellos textos de Navegación, que cumplían como mínimo, alguno de los siguientes requisitos:

- Que los autores hayan sido catedráticos o profesores de navegación.

- Que hayan sido declarados de texto para la formación de los pilotos.

- Los textos que en el periodo anterior a la constitución de la cátedra de navegación, pudieron servir de guía y ayuda en momentos en la que el proceso de formación de los pilotos pasaba por sus inicios, como pudieron ser las obras de: Martín Fernández de Enciso (1519), Francisco Faleiro (1535) y el de Martín Cortés (1551).

Con lo que se ha conseguido crear un corpus de textos de "Pilotage", en el que se ha cubierto un periodo que va comprendido de 1519 a 1606, compuesto por las siguientes obras y autores, ordenadas por orden cronológico:

- Martín Fernández de Enciso. Suma de geografía [...], 1519.

- Francisco Faleiro. Tratado del Sfphera y del arte del marear [...],1535.

- Pedro de Medina. Arte de navegar [...]. 1545.

- Martín Cortés. Breve compendio de la fphera y de la arte de navegar [...], 1551.

- Pedro Medina. Regimiento de navegación [...], 1552.

- Rodrigo Zamorano. Compendio de la Arte de Navegar [...], 1581.

- Andrés de Poza. Hidrografia. [...], 1585.

- Andrés García de Céspedes. Regimiento de navegación [...], 1606.

Para realizar el análisis de los textos seleccionados, se efectuó un recorrido por diversas investigaciones relacionadas con el análisis de textos, que nos permitiese la recogida y análisis de datos para obtener los objetivos establecidos. Para la búsqueda se tuvieron en cuenta las investigaciones realizadas sobre los modelos de valoración y comparación de textos matemáticos, entre los que destacan los trabajos de Schubring acerca de la metodología y análisis de textos de matemáticas; Ibáñez y 
Llombart sobre una propuesta metodológica para la valoración de los textos de Náutica; los de Monterrubio y Ortega sobre un modelo de valoración de textos matemáticos y los de Picado y Rico sobre el análisis de contenidos en textos históricos de matemáticas.

De los diferentes métodos tratados para analizar los textos, hemos utilizado el propuesto por lbáñez y Llombart al tratarse de una metodología elaborada exprofeso para textos de Náutica.

Una vez constituido el corpus de textos de "Pilotage", y para finalizar la fase heurística hemos realizado una ficha de cada uno de los libros y artículos seleccionados, que nos ha permitido tener clasificados los datos con los que hemos trabajado.

En la fase hermenéutica, hemos realizado una primera lectura de las obras desde una perspectiva general, resaltando los datos más destacables para nuestra investigación. Desde la que hemos pasado a la fase crítica, la externa y la interna. En la externa, en lo que se refiere a las fuentes manuscritas, hemos trabajado siempre con originales, lo que nos ha evitado realizar comprobaciones y comparaciones para certificarlos, en cuanto a los textos se ha verificado que no estuviesen dañados ni le faltasen hojas, también se han comprobado las correcciones de la erratas. En las actividades internas, en cuanto a las fuentes manuscritas, se han transcrito literalmente respetando su contenido, en cuanto han surgido dudas por la grafía empleada en el documento, se han resuelto mediante la comparación con otras transcripciones localizadas. En cuanto a los textos se ha respetado su literalidad y su sentido.

Por último, hemos realizado un análisis de los diferentes métodos astronómicos utilizados en los textos para el cálculo de la latitud observada por altura meridiana del Sol. Para lo cual seguimos la línea de investigación del contenido de los textos de Náutica, que permite rastrear la difusión de nuevas ideas o teorías científicas y que, al ser comparadas diacrónicamente, posibilitan a la vez, establecer la evolución de este método de posicionamiento astronómico en la mar, así como la de la formación de los pilotos ${ }^{71}$, que en este caso recibieron durante el periodo de estudio.

\section{Resultados}

Hemos analizado ocho textos de navegación, en los que la totalidad de los autores presentaban el cálculo de la latitud observada por meridiana de Sol y por la Polar, uno al paso por el meridiano inferior, tres por la Cruz del Sur y dos fuera de la meridiana. En este artículo, sólo desarrollamos la correspondiente al cálculo de la latitud observada por meridiana de $\mathrm{Sol}^{72}$. De los ocho textos analizados, los dos de Pedro de Medina comparten el mismo planteamiento en la exposición del cálculo de la latitud observada por meridiana de Sol, por lo que los presentamos en conjunto.

\footnotetext{
${ }^{71}$ IBÁÑEZ FERNÁNDEZ, Itsaso y LLOMBART, José. La comparación de textos en historia de la ciencia: Una propuesta metodológica. Llull, Revista de la Sociedad Española de Historia de las Ciencias y de las Técnicas. 2001, vol. 24, n. 49, pp. 140-142.

${ }_{72}$ Para el cálculo de la latitud observada por el paso del Sol por el meridiano superior del lugar, intervienen las siguientes variables: la altura observada del Sol (a) y su declinación (d).
} 
Partiendo de las variables $(d)$ y (a), los autores propusieron en sus textos diferentes procedimientos del cálculo de la latitud observada, en el que a las variables mencionadas añaden las reglas de las sombras ${ }^{73}$.

En el texto de Enciso, trata sobre el cálculo de la latitud por altura meridiana, en el apartado correspondiente al Regimiento del astrolabio y el cuadrante, sin incluir imágenes ni propone ejemplos. Inicia la explicación dando las fechas del 11 de marzo y el 14 de septiembre en las que el Sol no tiene declinación, avisa que hay que contar un día más en los años bisiestos y que los meses de marzo a agosto tiene signo positivo y negativo de septiembre a febrero. A partir de ahí y con los datos de la altura observada del Sol (a), su declinación (d) y las sombras, da dos sencillas reglas para el cálculo de la latitud observada en el caso del observador situado en el Sur:

- Observador situado en el Sur, declinación del Sol de la misma especie y las sombras a la parte del Sur, entonces $l o=(a-d)-90^{\circ}$.

- Observador situado en el Sur, declinación del Sol de la misma especie y las sombras a la parte del Norte, si $(a+d)>90^{\circ}$, entonces el exceso es el valor de lo. $\mathrm{Si}(a+d)=90^{\circ}$, nos encontramos debajo de la equinoccial.

Las mismas reglas sirven cuando el observador está situado en el Norte, teniendo en cuenta que si la declinación es Sur entonces se suma la altura y la declinación.

En el libro de Faleiro, en el capítulo VI da seis reglas para el cálculo de la latitud observada. Que denomina las seis reglas de las alturas:

- Primera regla. Cuando la altura observada del Sol es igual a 90ㅜㅡ, en ese caso el valor de la latitud será igual al valor de la declinación con su signo.

- Segunda regla. Cuando la declinación y la sombra son de la misma especie, entonces: $l o=\left(90^{\circ}-a\right)+d$ y la latitud será de la misma especie que la sombra.

- Tercera regla. Cuando la declinación y la sombra son de distinta especie, si $(a+d)=90^{\circ}$, el observador estará debajo de la equinoccial.

- Cuarta regla. Si en las condiciones de la tercera regla $(a+d)<90^{\circ}$, la diferencia hasta $90^{\circ}$ sería el valor de la latitud y de la misma especie que la sombra.

- Quinta regla. En el caso que $(a+d)>90^{\circ}$, el exceso será el valor de la declinación y de la misma especie.

- Sexta regla. Si $d=0$ y a $<90^{\circ}$; la diferencia hasta $90^{\circ}$ será el valor de la latitud y de la misma especie que las sombras.

En los textos de Medina para el cálculo de la latitud por altura meridiana, establecen 10 reglas, una para cada caso concreto acompañado de la figura correspondiente a la posición del observador según las situaciones del Sol y de las sombras, que agrupamos como sigue:

\footnotetext{
${ }^{73}$ Se considera sombra de un observador el punto del horizonte opuesto a un astro.
} 
- Cuando el Sol y sombras sean de la misma especie ${ }^{74}$, en ese caso: $l o=d+$ $\left(90^{\circ}-a\right)^{75}$, siendo la latitud de la misma especie que la declinación y las sombras. Propone un ejemplo resuelto.

- Cuando el Sol y sombras sean de diferente especie, en ese caso presenta tres supuestos:

- Si $a+d>90^{\circ}$, la cantidad que exceda de $90^{\circ}$ corresponderá al valor de la latitud observada que será de la misma especie que la declinación. Propone un ejemplo resuelto.

- Si $a+d<90^{\circ}$, la diferencia hasta $90^{\circ}$ corresponderá al valor de la latitud observada que será de la misma especie que las sombras. Propone un ejemplo resuelto.

- Si $a+d=90^{\circ}$, en ese caso el observador está en la línea equinoccial. Propone un ejemplo resuelto.

- Cuando el Sol está en el Zenit, en ese caso la latitud del observador será igual y de la misma especie que la declinación.

- Cuando el Sol en la línea equinoccial, en este caso presenta dos supuestos:

- Si $a<90^{\circ}$, la latitud tendrá el valor de la altura y de la misma especie que las sombras. Propone un ejemplo resuelto.

- Si $a=90^{\circ}$ y no hay sombras, el observador se encuentra en la línea equinoccial.

En el texto de Martín Cortés, en el capítulo octavo después de definir los conceptos de altura, complemento de la altura y altura meridiana, explica las tres formas de contar las sombras del Sol al mediodía que son, al Norte, al Sur o perpendicular, de acuerdo con las variaciones de la declinación, la altura y las sombras, da cuatro reglas para calcular la latitud, descartando por extensas las que utilizan los marineros.

- Regla primera: Si la sombra es perpendicular, el Sol está en el Zenit $a=90^{\circ}$, entonces $l=d$ y de la misma especie; si $d=0$ entonces $l=0$.

- Regla segunda: Si la declinación del Sol y las sombras son de la misma especie, entonces $l=90^{\circ}-(a-d)$ y de la misma especie que la declinación.

- Regla tercera: Si la declinación del Sol y las sombras son de la misma especie, entonces $(a+d)<90^{\circ}$ lo que falta para $90^{\circ}$ será el valor de la latitud y de la misma especie que las sombras; si $(a+d)>90^{\circ}$ el exceso será el valor de la latitud y de la misma especie que la declinación; si $(a+d)=90^{\circ}$ y $l=0^{\circ}$.

- Regla cuarta: Si $d=0^{\circ}$, entonces $l=90^{\circ}-a$ y de la misma especie de las sombras.

Zamorano en su libro una vez conocida la fabricación del instrumento que, explica en el capítulo primero, en el segundo capítulo pasa a explicar su uso y forma de tomar la altura del Sol con el astrolabio a la hora de la meridiana, teniendo en cuenta que es cuando tendrá la altura máxima, obtenida en el instante que se aprecie que el Sol esté parado, momento a partir del cual empieza a descender.

\footnotetext{
${ }_{75}^{74}$ Norte-Sur.

${ }^{75} 90^{\circ}-\mathrm{a}=3$.
} 
Primero explica las Reglas de las sombras, que pueden ser de tres maneras teniendo en cuenta hacia dónde va la sombra en el momento del medio día, la primera, cuando coincide la sombra con donde el Sol tiene su declinación, la segunda cuando no coincide, en estos dos casos, la altura del Sol es menor de $90^{\circ}$ y la tercera es cuando no hay sombra, esto ocurre cuando el Sol tiene una altura de 90, amplía estas reglas poniendo un ejemplo de cada una de ellas.

Conocidas las Reglas de las sombras pasa al Regimiento y Reglas del Sol, dando cinco reglas para determinar la latitud del observador en el momento de la meridiana, de las cuales propone ejemplos:

- La primera fija la especie que tiene la declinación del Sol en función de las fechas; Norte desde el 11 de marzo hasta el 13 de septiembre y Sur del 14 de septiembre al 10 de marzo.

- La segunda establece que cuando $a=90^{\circ}$ entonces $l o=d$ y de la misma especie que la declinación.

- La tercera trata del cálculo a realizar cuando la altura del Sol es inferior a 90ํy $d=0^{\circ}$, entonces $l o=3$ y de la misma especie que las sombras.

- La cuarta regla corresponde a cuando el Sol y sombras van a una misma parte, entonces $l o=3+d$ y de la misma especie que Sol y Sombras.

- En la quinta trata del cálculo a realizar cuando Sol y sombras son diferentes estableciéndose dos supuestos: Si $a+d=90^{\circ}$ entonces $l o=0^{\circ}$; Si $a+d<90^{\circ}$ entonces $l o=(a+d)-90^{\circ}$ y de la especie de las Sombras.

Poza en el capítulo cuarto de la cuarta parte del libro primero, da 5 reglas para el cálculo de la latitud observada por altura meridiana del Sol:

- Regla primera: Si $a=90^{\circ}$ y nos encontramos a 21 de marzo o 23 de septiembre, en tal caso nos hallamos bajo la línea y los Polos está en el horizonte.

- Regla segunda: Si $a=90^{\circ}$ y nos encontramos entre el 22 de marzo y 22 de septiembre incluidos, estaremos en entre el trópico de cáncer y la línea equinoccial, el valor de la latitud será igual al que tenga la declinación el día de la observación. Pero si $a=90^{\circ}$ y nos encontramos entre el 24 de septiembre y 20 de marzo, estaremos a la banda del Sur, entre la línea equinoccial y el trópico de capricornio, en este caso el valor de la latitud coincidirá con el que tenga la declinación el día de la observación.

- Regla tercera: Caso que el observador esté entre el trópico de cáncer y el Norte: si nos encontramos a 21 de marzo o 23 de septiembre, haremos $l o=90^{\circ}-(a+$ d); pero si nos encontramos entre 23 de septiembre y 21 de marzo, haremos $l o=90^{\circ}-(a+d)$. En este caso la denominación de la latitud será Norte.

- Regla cuarta: Caso que el observador esté entre el trópico de capricornio y el Polo Antártico: si nos encontramos entre el 21 de marzo o 23 de septiembre, haremos $l o=90^{\circ}-(a+d)$; pero si nos encontramos entre 23 de septiembre y 21 de marzo, haremos $l o=90^{\circ}-(a+d)$. En este caso la denominación de la latitud será Sur.

- Regla quinta: De utilidad entre los trópicos donde las sombras y la equinoccial entre año son diferentes. Si la declinación del Sol y las Sombras son de diferente especie y la $(a+d)=90^{\circ}$ estamos en la equinoccial; si $(a+d)>90^{\circ}$ el exceso es lo que estaremos sobre la equinoccial hacia la parte del Sol; si $(a+d)<90^{\circ}$ 
el defecto será lo que estaremos sobre la equinoccial.

En el texto de García de Céspedes trata sobre la altura del polo calculándolo mediante las sombras, es el primer autor de los analizados que utiliza la aguja de marear para reconocer a que banda van las sombras y propone las siguientes reglas:

- Sol y sombras a una parte: $l o=\left(90^{\circ}-a\right)+d$, la latitud será de la misma especie que la declinación. Realiza la demostración de la regla apoyándose en la Figura 3, a partir de la cual deduce gráficamente el valor y la denominación de la latitud, $g a=h a+g h^{76}$, de la misma denominación que la declinación.

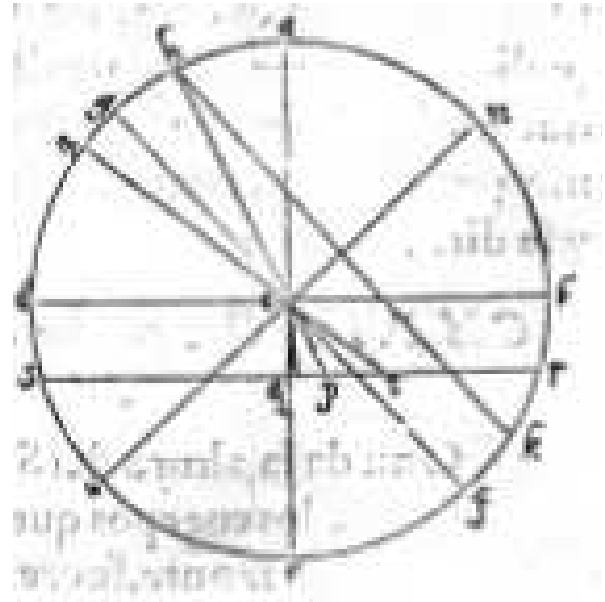

Fig. 3: llustración utilizada por García de Céspedes (1606) para la demostración gráfica de la primera regla. Fuente: García de Céspedes, $1606^{77}$.

- Sol y sombras a diferente parte, dos supuestos:

- Primer supuesto. Si $\left(90^{\circ}-a\right)=d$, entonces $l=0$. Mediante la Figura 4, deduce gráficamente que en este caso (ac) será la equinoccial y (bd) los polos en el mismo horizonte. Al distar el punto (a), de los puntos (b y d) un cuadrante, al ser (bd) el horizonte, (a) será el zenit y al ser (hk) el paralelo del Sol y (dh) su altura, tendremos que (ha) es el valor de la declinación que será igual al complemento de la altura, entonces (ac) será la equinoccial y (bd) los polos del mundo. En este caso la sombra será de distinta denominación que la declinación como se ve en la Figura 4, la sombra del estilo (qe) está en (p).

\footnotetext{
${ }^{76}$ Teniendo en cuenta que: abc: el meridiano; e: El centro del mundo desde donde se hacen las observaciones; n: polos del mundo; fg: la equinoccial; hk: paralelo del Sol; bd: horizonte; a: zenit; dh: altura del Sol sobre el horizonte; h: punto donde se encuentra el Sol; gh: declinación del Sol; rs: plano paralelo al horizonte; qe: la sombra; qp: a la parte del polo $\mathrm{n}$.

7 GARCÍA DE CÉSPEDES, Andrés. Regimiento de navegacion que mando hacer el Rei nuestro Señor por orden de su consejo Real de las Indias a Andres Garcia de Cespedes su Cosmografo Mayor siendo Presidente en el dicho consejo el conde de Lemos. Madrid: En casa de luan de la Cuesta, 1606, fol. 27.r
} 


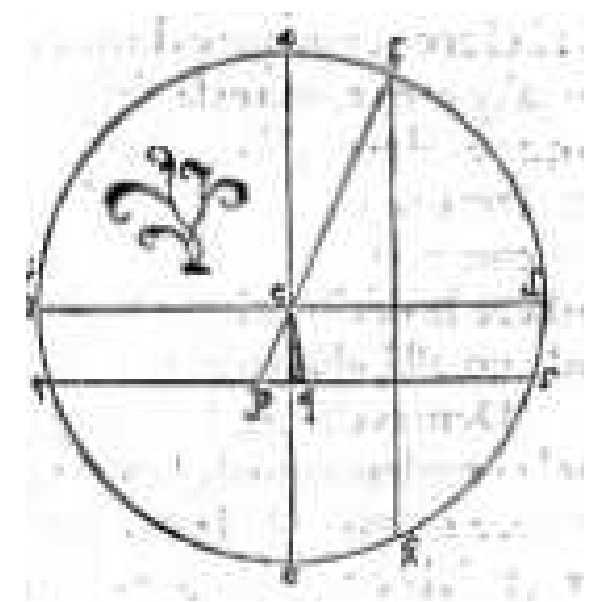

Fig. 4: Ilustración utilizada por García de Céspedes (1606) para la demostración gráfica de la segunda regla, primer supuesto. Fuente: García de Céspedes, $1606^{78}$.

- Segundo supuesto. Si $\left(90^{\circ}-a\right)<d$ entonces $l=d-\left(90^{\circ}-a\right)$ y de la misma denominación que la declinación, de acuerdo con la Figura 5, realiza la demostración de la regla apoyándose en la Figura 3, a partir de la cual deduce gráficamente el valor y la denominación de la latitud $a g=h g+h a$.

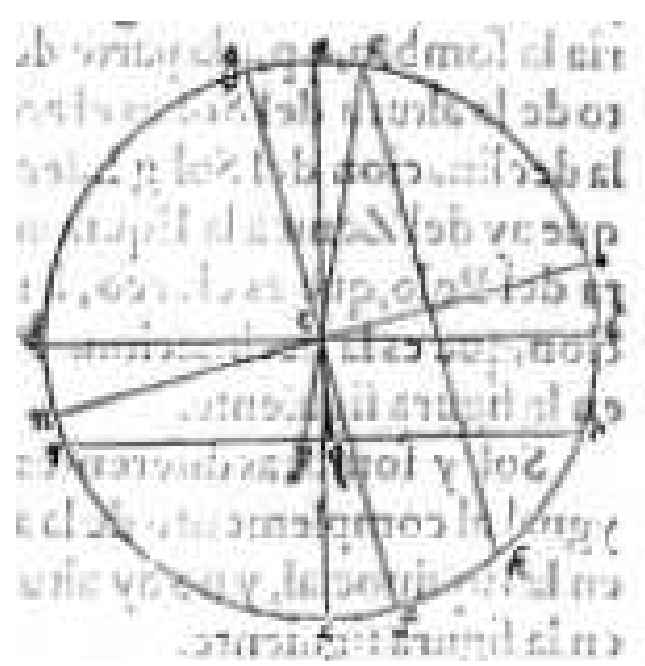

Fig. 5: Ilustración utilizada para la demostración gráfica de la segunda regla, segundo supuesto.

Fuente: García de Céspedes, $1606^{79}$.

- Tercer supuesto. Si $\left(90^{\circ}-a\right)>d$ entonces $l=\left(90^{\circ}-a\right)-d$ y de distinta denominación que la declinación. De acuerdo con la Figura 6, realiza la demostración gráfica, en la que $a g=g h-h a^{80}$ y de la misma denominación que la declinación y la sombra que hace el Sol en (h) será el punto $p$ contrario a la declinación.

\footnotetext{
${ }^{78}$ GARCÍA DE CÉSPEDES, Andrés. Regimiento de navegacion. Op. cit., fols. 28.v- 28r.

${ }^{79}$ GARCÍA DE CÉSPEDES, Andrés. Regimiento de navegacion. Op. cit., fol. 28r.

80 Teniendo en cuenta que: abc: el meridiano; e: El centro del mundo desde donde se hacen las observaciones; n: polos del mundo; fg: la equinoccial; hk: paralelo del Sol; bd: horizonte; a: zenit; dh: altura del Sol sobre el horizonte; h: punto donde se encuentra el Sol; gh: declinación del Sol; rs: plano paralelo al horizonte; qe: la sombra; qp: a la parte del polo $\mathrm{n}$.
} 


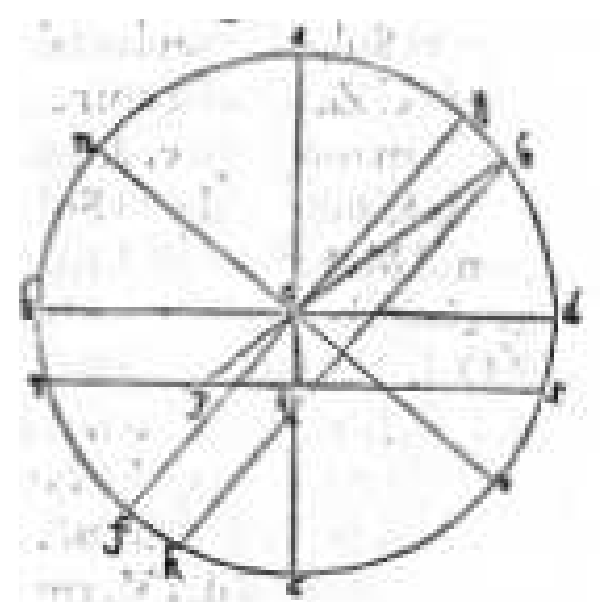

Fig. 6: llustración utilizada por García de Céspedes (1606) para la demostración gráfica de la segunda regla, tercer supuesto. Fuente: García de Céspedes, $1606^{81}$.

Cuando el Sol no tiene declinación. En este caso considera que el Sol se encuentra en (g) y la altura del polo coincide con el complemento de la altura (ga) y las sombras irán al punto (p). En este caso, para la demostración gráfica el autor utiliza la misma figura que en el caso anterior.

\section{Conclusiones}

Los viajes a las Indias significaron una nueva realidad para los pilotos. Las navegaciones ya no se hacían a la vista de la costa, el piloto navegaba por parajes alejados de ella, en esta nueva realidad, las navegaciones se realizaban sin más referencia que el cielo. La aguja, la sonda y la experiencia ya no eran suficientes para llegar al punto de destino, se requerían unos conocimientos que los pilotos, generalmente no tenían y en muchos casos eran reticentes a adquirirlos. Disciplinarlos constituyó un reto importante para la Corona, al tratarse de un colectivo que no solo no había recibido ningún tipo de formación académica, sino que, la mayoría no sabían leer ni escribir, a lo que había que unir sus escasas posibilidades económicas, que no les permitía permanecer mucho tiempo desembarcado para atender a su formación. Por lo tanto, encontrar la fórmula que resolviese ese problema, no era tarea fácil. La solución que se adoptó inicialmente fue la de tratar que los pilotos y marineros que estaban realizando la Carrera de Indias, fuesen formados y examinados por el piloto mayor de la Casa de Contratación de Sevilla para obtener el título de Piloto de la Carrera de Indias. Pero el problema de la escasa formación técnica de los pilotos siguió persistiendo, como lo reflejaron las Reales Cédulas de 1527 y la de 1552.

El nombramiento de un catedrático de cosmografía y navegación, junto con la instauración de un plan de estudios muy amplio, para la formación de los pilotos, la obligatoriedad de asistir durante un año a la lectura de la cátedra, con el requisito de haber navegado previamente a las Indias, parecía estar destinado a resolver el problema que se arrastraba desde el inicio de los viajes oceánicos. Pero no fue así, debido al divorcio existente entre lo que se reflejaba en el papel, es decir, lo que se

${ }^{81}$ GARCÍA DE CÉSPEDES, Andrés. Regimiento de navegacion. Op. cit, fol. 28r-29v. 
debe hacer y lo que realmente se estaba dispuesto a hacer para formar a los pilotos. ¿Cuál fue el verdadero motivo que llevó a reducir drásticamente la lectura de la cátedra? ya que no consideramos válido el argumento de la pobreza de la gente de mar, para justificar la reducción del periodo de oír la lectura de la cátedra, porque la pobreza no les devino de súbito. La pregunta es: ¿se hizo un plan de estudios ambicioso, para justificar la creación de un cargo científico de acuerdo con el perfil del bachiller Jerónimo de Chaves hijo del piloto mayor Alonso de Chaves, a sabiendas de que el plan en ese momento era impracticable? No sería descabellado pensar que primaron más los nombramientos de cargos científicos, que el fin al que estaban destinados.

La rápida reducción del periodo lectivo y el conocimiento que tenemos de cómo hacía y que preguntaba en los exámenes de piloto, Alonso de Chaves, nos hacen pensar que, a pesar de ser una idea acertada y necesaria la figura del catedrático de cosmografía y navegación, poco supuso en el adelanto de la formación de los pilotos de la Carrera de Indias durante el periodo estudiado.

Sobre el papel y teniendo en cuenta el momento en que se promulgaron, consideramos a todos los planes de estudios, adecuados. Por lo que sabemos, en la práctica, no fue así, de 1508 a 1527 no se conoce cómo se realizaba ni la enseñanza ni los exámenes, en adelante, tenemos conocimiento que, el periodo de estudio duraba dos meses incluidos los festivos y las preguntas que se hacía eran de corte elemental y así continuó durante todo el periodo de estudio.

Como se ha podido constatar por el estudio de las Reales Cédulas de 1508, 1527, 1552 y 1636, la Corona legisló planes de estudio para los pilotos adecuados al momento, pero no se ocupó de que estos se cumpliesen para que estos estuviesen debidamente formados.

El trabajo con los textos de "Pilotage" que corresponden a los editados para la formación de pilotos entre 1508 y 1700, nos ha dado una idea del procedimiento utilizado para calcular la latitud observada por altura meridiana, en el que mediante la altura del Sol, su declinación y la posición de las sombras, cada autor propone una serie de reglas a memorizar para obtener la latitud observada. Solo Medina, y Zamorano aprovechan el recurso pedagógico que implica utilizar ejemplos para reforzar lo explicado mientras que Medina y García de Céspedes lo apoyan con figuras.

En general hemos podido constatar que se pretendía que el piloto supiese calcular la latitud por métodos nemotécnicos y memorizados, ausente de la utilización del razonamiento y del aparato matemático. En el que los diversos autores llegan al mismo resultado empleando un número distinto de reglas, pero con la misma rusticidad. El método para calcular la latitud observada por altura meridiana, en los textos, no evolucionó durante el periodo de estudio, ninguno de los autores ofreció una fórmula general para su determinación, por lo que se siguió utilizando las tradicionales Reglas del Sol. 
En el periodo estudiado no se utilizaba aún la formula general:

$$
10=d-3
$$

en donde se consideran positivas las latitudes (I) y declinaciones (d) Norte y negativas las Sur, en cuanto a la distancia zenital (3) será positiva o negativa según se efectúe la observación cara al Norte o al Sur, de acuerdo con si (d) $>$ I entonces (3 ) (+) y cara al Norte; si (d) < I entonces (3 ) (-) y cara al Sur.

Los conocimientos básicos sobre astronomía náutica utilizada en la formación de los pilotos eran los incluidos en los libros I y II de la Esfera constituyendo la materia propedéutica para calcular latitud observada.

Del análisis efectuado se desprende que, los procedimientos analizados son de carácter elemental, dirigidos a gente con escasa cultura y larga experiencia en la mar, redactados a modo de recetario de tal forma que pudiesen comprender y asociar lo aprendido durante las navegaciones a las Indias con la parte teórica, que se impartía en la lectura de la cátedra y de esta forma estar capacitador para realizarlo autónomamente. El contrapunto lo pone la obra de García de Céspedes (1606) en la que emplea las matemáticas de forma natural para realizar las operaciones que soporta mediante la inclusión de figuras. El nivel de sus contenidos, no están ideados para un piloto de la época, sino para aquellos que previamente tuviesen conocimientos de aritmética, de los elementos de Euclides y de la trigonometría plana y esférica. Lo que lo convertía en un texto ideal para los estudiantes de 3er año del plan de 1636 del Real Consejo de Indias (que no llegó a entrar en vigor). Por lo que, podemos decir que Andrés García de Céspedes, se anticipó en muchos años, en plasmar en un texto los contenidos que debían poseer los pilotos.

\section{Bibliografía}

ANÓNIMO. Recopilación de Leyes de los Reynos de las Indias mandadas imprimir, y publicar por la Magestad Católica del Rey Don Carlos II Nuestro Señor. Vol. I. Madrid: Julián de Paredes, 1841.

ANÓNIMO. Recopilación de las leyes de los Reinos de las Indias, mandada imprimir y publicar por la Magestad Católica del Rey Don Carlos II, Nuestro Señor. Vol. III. Madrid: Boix, 1841.

ARROYO RUIZ-ZORRILLA, Ricardo. Apunte para una historia de la enseñanza de la náutica en España. Madrid: Centro de Publicaciones del Ministerio de Transportes Turismo y Comunicaciones, 1989.

CAPEL, Horacio. Geografía y Matemáticas en la España del siglo XVIII. Barcelona: Oikos-tau, 1982.

CAPMANY Y DE MONPALAU, Antonio. Código de las costumbres marítimas de Barcelona, hasta aquí vulgarmente llamado libro del consulado. Madrid: 
Imprenta de Don Antonio Sancha, 1791.

CEDILLO Y RUJAQUE, Pedro Manuel. Tratado de cosmografía y nautica. Cádiz: En la imprenta Real de Marina y Casa de la Contratación de Don Miguel Gómez Guiraun, 1745.

CÉSPEDES DEL CASTILLO, Guillermo. La defensa de América. En: RUIZ MARTíN, F. La monarquía de Felipe II. Madrid: Real Academia de la Historia, 2003, pp. 381-412.

CORONA BARATECH, Carlos Eduardo Y ARMILLAS VICENTE, José Antonio. Historia General de España y América: La España de las Reformas Hasta el final del Reinado de Carlos IV. Vol. X-2. Madrid: Rialp, 1990.

CORTÉS, Martín. Breve compendio de la fphera y de la arte de navegar/con nuevos instrumentos y reglas/ejemplificado con muy subtiles demonstraciones: compuesto por martin Cortes natural de burjalaroz en el reyno de Aragon y de prefente vezino de la ciudad de cadiz:dirigido al invictiffimo Monarca Carlo Quinto Rey de las Efpañas etc. Sr. Nuestro. 1551.

ESCALANTE DE MENDOZA, Juan. Itinerario de navegación. Madrid: Museo Naval (1985), 1575.

ESTEBAN PIÑEIRO, Mariano. Las academias técnicas en la España del siglo XVI. Quaderns dl'historia de lénginyeria. 2002, n. 5, pp. 10-19.

ESTEBAN PIÑEIRO, Mariano. Ciencia Imperial: Casa de Contratación. El Escorial. El Alcázar. En: SARAIVA, T. y VALVERDE, N. Momentos y lugares de la ciencia Española siglos XVI-XX. Madrid: Antonio Lafuente y Juan Pimentel, 2012, pp. 19-32.

FALEIRO, Francisco. Tratado del Sfphera y del arte del marear: con el regimiento de las alturas: con algunas reglas nuevamente escritas muy neffearias. Sevilla, 1535.

FERNÁNDEZ DE ENCISO, Martín. Suma de geografía que trata de todas las partidas et provincias del mundo, en especial de las Indias, y trata largamente del arte del marear, juntamente con la espera en romance, con el regimiento del sol et del norte. Sevilla: Jacobo Cromberger, 1519.

FERNÁNDEZ DE NAVARRETE, Martín. Colección de los viages y descubrimientos que hicieron por mar los españoles desde fines del siglo XV. Vol. 3. Madrid: Imprenta Real, 1829.

FERNÁNDEZ DE NAVARRETE, Martín. Biblioteca Marítima Española. Madrid: Imprenta de la viuda de Calero, 1851. 2 Volúmenes.

FERNÁNDEZ DURO, Cesáreo. Disquisiciones Náuticas. Arca de Noé. Vol. 6. 
Madrid: Imprenta, Estereotipia y Galvanoplastia de Aribau y C. Sucesores de Rivadeneyra, 1881.

GARCÍA DE CÉSPEDES, Andrés. Regimiento de navegacion que mando hacer el Rei nuestro Señor por orden de su consejo Real de las Indias a Andres Garcia de Cespedes su Cosmografo Mayor siendo Presidente en el dicho consejo el conde de Lemos. Madrid: En casa de luan de la Cuesta, 1606.

GARCÍA DE PALACIO, Diego. Instrucción náutica, para el buen uso, y regimiento de las naos, su traza, y gobierno conforme a la altura de México. México: En casa de Pedro Ocharte, 1587.

GARCÍA FRANCO, Salvador. Historia del arte y ciencia de navegar. Desenvolvimiento histórico de los cuatro términos de la navegación. Madrid: Instituto histórico de Marina, 1947. 2 Volúmenes.

GELCICH, Eugen. Estudios sobre el desenvolvimiento histórico de la navegación: especialmente referidos a las ciencias náuticas. Valencia: Librería de Pascual Aguilar, 1889.

GONZÁLEZ GONZÁLEZ, Francisco José. Astronomía y navegación en España siglos XVI-XVIII. Madrid: Mapfre, 1992.

GUILLEN TATO, Julio Fernando. Europa aprendió a navegar en libros españoles. Barcelona: Contribución del Museo Naval de Madrid a la exposición del Libro del Mar, 1943.

IBÁÑEZ FERNÁNDEZ, María del Mar. La difusión de conocimientos náuticos en la España decimonónica: La navegación astronómica en los textos de náutica españoles del siglo XIX. Bilbao: Universidad del País Vasco, 2000.

IBÁÑNZ FERNÁNDEZ, Itsaso y LLOMBART, José. La comparación de textos en historia de la ciencia: Una propuesta metodológica. Llull, Revista de la Sociedad Española de Historia de las Ciencias y de las Técnicas. 2001, vol. 24, n. 49, pp. 131-148.

IGLESIAS MARTÍN, María Asunción. Estudio comparativo desde el punto de vista matemático de textos náuticos españoles del siglo XVIII. Leioa: Servicio Editorial de la Universidad del País Vasco, 2000.

LAGUARDA TRIAS, Rolando Agustín. Comentarios sobre los orígenes de la navegación astronómica. Madrid: Consejo Superior de Investigaciones Científicas. Instituto Histórico de Marina, 1959.

LÓPEZ, Gregorio. Las siete partidas del Rey Don Alfonso el Sabio. Cotejada por el Lic. Gregorio López. Vol. 2. Segunda y Tercera partida. París: Lecointe y Laserre, 1843. 
LÓPEZ PIÑERO, José María. Ciencia y técnica en la sociedad española de los siglos XVI y XVII. Barcelona: Labor, 1979.

LÓPEZ PIÑERO, José. María. El Arte de Navegar en la España del Renacimiento. Barcelona: Labor, 1986.

LULIO, Raimundo. Arbol de la ciencia de el muy iluminado maestro Raymundo Lulio (Traducido por Alonso de Cepeda y Adrada). Bruselas: Francisco Foppens, Impresor y mercader de libros, 1664.

MARTÍN-MERÁS, Luisa. Las enseñanzas náuticas en la Casa de la Contratación de Sevilla. En: ACOSTA, A.; GONZÁLEZ, A. y VILA, E. (coord.) La Casa de la Contratación y la navegación entre España y las Indias. Sevilla: Universidad de Sevilla; CSIC; Fundación EI Monte, 2004, pp. 667-693.

MANTEROLA ZABALA, Juncal. Las Matemáticas en los Estudios de Náutica en España en el Siglo XVIII: Estudio Comparativo de los Libros de Texto empleados en la Formación de Pilotos y Guardiamarinas [tesis doctoral]. La Rioja: Universidad de la Rioja, 2016.

MEDINA, Pedro. Arte de navegar en que fe contienen todas las Reglas, Declaraciones, Secretos, y Avisos, q a la buena navegación son necceffarios, y fedeve faber, hecha por el maestro Pedro de Medina, Dirigida al fereniffimo y muy efclarefcido feñor, don Phelipe príncipe de España, y de las dos Sicilias. Valladolid, 1545.

MEDINA, Pedro. Regimiento de navegación. Contiene las cosas que los pilotos han de saber para bien navegar: y los remedios y avisos que han de tener para los peligros que navegando les pueden suceder. 1552.

MEDINA, José Toribio. El Veneciano Sebastián Caboto al servicio de España. Vol. 1: Texto. Santiago de Chile: Imprenta y Encuadernación Universitaria, 1908.

MENA GARCÍA, María del Carmen. Sevilla y las flotas de Indias: La Gran Armada de Castilla del Oro (1513-1514). Sevilla: Universidad de Sevilla; Fundación Cultural El Monte, 1998.

MONTERRUBIO, María Consuelo y ORTEGA, Tomás. Creación de un modelo de valoración de textos matemáticos. Aplicaciones. En: GONZÁLEZ, María José; GONZÁLEZ, María Teresa y MURILLO, Jesés (eds.). Investigación en Educación Matemática XIII. Santander: SEIEM, 2009, pp. 37-53.

NAVARRO GARCÍA, Luis. Pilotos, maestres y señores de naos en la carrera de las Indias. Revista histórica, literaria y artística. 1967, vol. 46, n. 141, pp. 241-298.

NAVARRO BROTONS, Víctor. Disciplina saberes y prácticas. Filosofía natural, matemáticas y astronomía en la sociedad española de la época moderna. Valencia: Universitat de Vàlencia, 2014. 
Ordenanzas reales para la casa de la Contratación de Sevilla y para otras cosas de las Indias: y de la navegación y contratación dellas. Sevilla, 1553.

PALAU CLAVERAS, Agustín. Ensayo de bibliografía marítima española. Valladolid: Maxtor, 2010.

PÉREZ-MALLAínA, Pablo Emilio. Andalucía y el dominio de los espacios oceánicos. La organización de la Carrera de Indias en el siglo XVI. Fundación Corporación Tecnológica de Andalucía, 2010.

PÉREZ-MALLAÍNA BUENO, Pablo Emilio. Naufragios en la Carrera de Indias durante los siglos XVI y XVII: El hombre frente al mar. Sevilla: Universidad de Sevilla, 2015.

PICADO, Miguel y RICO, Luis. Análisis de contenido en textos históricos de matemáticas. PNA. 2011, vol. 6, n. 1, pp. 11-27.

PICATOSTE RODRÍGUEZ, Felipe. Biblioteca científica española del siglo XVI, Madrid, Estudios biográficos y bibliográficos de ciencias exactas físicas $y$ naturales $y$ sus inmediatas aplicaciones en dicho siglo. Madrid: Imprenta y fundación de Manuel Tello, 1891.

PINTOS, Gabriel y IBÁÑEZ, Itsaso. Antonio de Gaztañeta e Iturribalzaga (16561728): Notas biográficas inéditas. Llull, Revista de la Sociedad Española de Historia de las Ciencias y de las Técnicas. 2019, vol. 42, n. 86, pp. 99-119.

POZA, Andrés. Hydrografia la mas curiosa que hasta aquí ha salido a luz, en que de mas de un derrotero general, fe enfeña la navegación por altura y derrota, y la del Efte Oefte: con la Graduacion de los puertos, y la navegación al Catayo por cinco vías diferentes. Compuefto por el Licenciado Andres de Poça natural de la ciudad de Orduña abogado e el muy noble leal Señorio de Vizcaya. Bilbao: Mathias Mares, 1585.

PUENTE OLEA, Manuel. Los trabajos geográficos de la casa de la contratación. Sevilla: Escuela tipográfica y librería Salesianas, 1900.

PULIDO RUBIO, José. El Piloto Mayor de la casa de Contratación de Sevilla. Pilotos mayores, catedráticos de cosmografía y cosmógrafos. Sevilla: Escuela de Estudios Hispano Americanos, 1950.

REY PASTOR, Julio. La ciencia y técnica en el descubrimiento de América. Buenos Aires: Espasa Calpe, 1970.

SALAVERT FABIANI, Vicent Lluis. La cultura científico técnica en la España de los siglos XVI y XVII. Bulletin Hispanique. 1995, vol. 97, n. 1, pp. 233-259.

SALVÁ, M. y SAINZ DE BARANDA, Pedro. Colección de documentos inéditos para la historia de España. Vol. XXI. Madrid: Imprenta de la Viuda de Calero, 1852. 
SÁNCHEZ MARTíNEZ, Antonio. La voz de los artesanos en el Renacimiento científico: Cosmógrafos y cartógrafos en el preludio de la nueva filosofía natural. Arbor Ciencia, Pensamiento y Cultura. May./jun., 2010, vol. CLXXXVI.

SÁNCHEZ MARTíNEZ, Antonio. Los artífices del Plus Ultra: Pilotos, cartógrafos y cosmógrafos en la Casa de la Contratación de Sevilla durante el siglo XVI. Hispania. Revista Española de Historia. 2010, vol. LXX.

SÁNCHEZ MARTíNEZ, Antonio. Los métodos pedagógicos de la Corona para disciplinar la experiencia de los navegantes en el siglo XVI. Anuario de estudios americanos. 2010, vol. 67, n. 1.

SCHAFER, Ernesto. El Consejo Real y Supremo de la Indias: Historia y organización del Consejo y de la Casa de la Contratación de las Indias. Madrid: Marcial Pons, Ediciones de Historia, 2003. 2 Volúmenes.

SCHUBRING, Gert. On the methodology of analysing historical textbooks: Lacroix as textbook autor. Fort the Learning of Mathematics. 1987, n. 7, pp. 41-51.

SCHUBRING, Gert. Discussions épistémologiques sur le tatut des Nombresnégatifs et leur représentation das les manuels allemands et français de mathématique entre 1795 et 1845. Actes du premier colloque francoallemand de didáctique des mathématiques et del'informatique. Editions La Pensée Sauvage, 1988.

SCHUBRING, Gert. Changing cultural and epistemological views on mathematics and different institutional contexts in nineteenth-century Europe. In: GOLSTEIN, C.; GRAY, J. and RITTER, J. (eds.). L'Europe mathématique: Histries, mythes, indentités. Paris: Editions de la maison des sciences de l'Home, 1996, pp. 363388.

VICENS VIVES, Jaime. Historia Económica de España. Barcelona: Vicens - Vives, 1977.

VEITIA LINAJE, José. Norte de la Casa de Contratación de las Indias Occidentales. Sevilla: Juan Francisco de Blas, 1672.

ZAMORANO, Rodrigo. Compendio de la Arte de Navegar de Rodrigo Zamorano, Astrólogo Y Matemático, y Cosmógrafo de la Majestad Católica de Don Felipe segundo Rey de España, y su catedrático de Cosmografía en la casa de la Contratación de las Indias de la Ciudad de Sevilla. Al muy llustre Señor el Licenciado Diego Gasca de Salazar, Presidente en el Consejo Real de las Indias. Sevilla: Alonso de la Barrera, 1581.

ZARAGOZA Y VILANOVA, José de. Esfera en común celeste y terráquea. Madrid: Juan Martín del Barrio, 1675. 